Volume (4) No. (3) 2021

نموذج الشـرائط البصرية: سر تميز تلاميذ سنغافورة في الرياضيات

أ.د. رضا مسعد السعيد 


\section{نموذج الشرائط البصرية: سر تميز تلاميذ سنغافورة في الرياضيات \\ أ.د. رضامسعد السعيد}

أستاذ تعليم الرياضيات، كلية التربية جامعة دمياط، مصر

rmasar@hotmail.com

\section{قبلت للنشر في 2021/6 - 2021}

قدمت للنشر في 2021/

الملخص: هدف هذا البحث الي تعريف الباحثين في تربويات الرياضيات ومعلمي الرياضيات ومطوري مناهج الرياضيات في مصر والوطن العربي بسر تفوق وتميز تلاميذ سنغافورة في الرياضيات واحتفاظهم بالمراكز الاولي في الدراسة الدولية لتوجهات تعليم العلوم والرياضيات بدوراتها المتعاقبة كل أربع سنوات. ويكمن هذا السر في عدد من النماذج المجتمعية والمدرسية والاسرية و الصفية من أهمها نموذج المريج الشرائط المصورة الذي يقدم حلو لا سحرية لأي مشكلة رياضية بكل سهولة ويسر. ان حل المشكلات هو مركز أو بؤرة تعليم الرياضيات نظر الأنه يتضمن اكتساب وتطبيق المفاهيم والمهارات الرياضية في نطاق واسع من المواقف التي تتضمن مشكلات العالم الحقيقي، والمشكلات مفتوحة النهاية وغير الروتينية. ويستخدم نموذج المودل السنغافوري في حل المشكلات اللفظية حيث يقوم التلميذ بتحديد المعلومات الرئيسية في المشكلة في نموذج تصويري يشتمل على وحدات في شكل مستطيلات ويتم

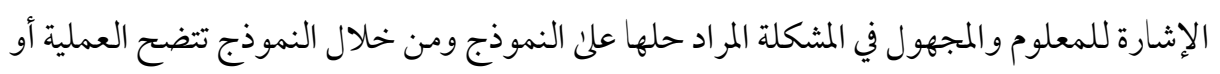
العمليات الحسابية الواجب استخدامها ويتم حل المشكلة.

الكلمات المفتاحية: نموذج الشرائط البصرية، تعليم الرياضيات، سنغافورة، التميز في الرياضيات 


\title{
Pictorial Model: The Secret of Singapore's Pupils' Excellence in
} Mathematics

\author{
Prof. Dr. Reda Mossad Elsaid \\ professor of Mathematics Education, Damietta University, Egypt \\ rmasar@hotmail.com
}

Presented in 26th March 2021

Accepted in 1st June 2021

\begin{abstract}
The research aimed to introduce mathematics education researchers, mathematics teachers and developers of mathematics curricula in Egypt and the Arab world with the secret of excellence of Singapore students in mathematics and how they come at the top order in the international study of the trends of science and mathematics education every four years. This secret lies in a number of communities, school, family and classroom models, the most important of which is the pictorial model, which offers magic solutions to any mathematical problem. Problem solving is the center or focus of mathematics education as it involves acquiring and applying mathematical concepts and skills in a wide range of situations involving real-world problems, open-ended and non-routine problems. The Singaporean model is used to solve verbal problems where the student identifies the main information in the problem in a pictorial model that includes units in the whole figure of rectangles and the information and the unknown is indicated in the problem to be solved on the pictorial figure and through the figure the process or calculations to be used are clarified and the problem is resolved.
\end{abstract}

Key words: Pictorial Model, Mathematics Education, Singapore, Excellence in Mathematics 
سنغافورة هي دولة صغيرة تقع في جنوب شرق آسيا وتعتبر صاحبة المركز الاول في تحصيل الرياضيات علن مستوي العالم. واستطاعت تلك الدولة الصغيرة أن تحافظ علن حصد تلاميذها للمركز الأول في الرياضيات. وادي ذلك التقدم المبهر في تعليم الرياضيات في سنغافورة الي اهتحام باحثي ومعلمي الرياضيات حول العالم بسر نجاح سنغافورة في محاولة منهم للتعرف علن أسباب تفوق تلاميذ سنغافورة علن التلاميذ في كثير من الدول الأخرىن في تحصيل الرياضيات (Clark, 2009). ويشتمل منهج الرياضيات في سنغافورة على مجموعة من استراتيجيات تدريس الرياضيات تتمركز حول حل المشكلات ويؤكد علن المهارات التي يحتاجها التلميذ ليكون مفكرا جيدا ولا يركز علن المهارات الإجر ائية والحفظ الروتيني (Chen, et.al, 2010). ويشير هو جان (Hogan, 2004,22)

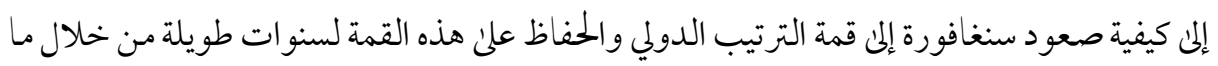

1- قامت سنغافورة بتغييرات مهمة علن المنهج الدراسي حيث يدرس تلاميذ سنغافورة الآن موضوعات أقل في الرياضيات كل عام، ولكن بعمق كبير، وتم التقليل من المعلومات

$$
\text { وحذف الموضوعات الغريبة والمكررة. }
$$

2- يشتمل منهج رياضيات سنغافورة علن محتوى رياضياتي عال وقون يؤكد علن بناء الحس وحس

$$
\text { العددي ومهارات التفكير العليا. }
$$

3- الكتب الدراسية في الرياضيات في سنغافورة تعرض المفاهيم باستخدام الصور، والأعداد،

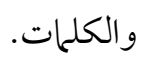

4- يبدأ محتوي منهج الرياضيات في سنغافورة بالتعلم الملموس والمحسوس وتنتقل إلى التعلم

$$
\text { التصويري وتنتهي بالتعلم المجرد. }
$$

5- مدخل البسيطة والمركبة حل المشكلات هو العنصر الرئيس في منهج الرياضيات في

سنغافورة. 
6- يتعلم التلاميذ استخدام نموذج الشرائط التصويرية في المرحلة الابتدائية ويستمرون في استخدامه، ومع الممارسة المستمرة له تصبح كفاءتهم عالية في حل المشكلات المعقدة جدًا.

ما أسباب الاهتحام العالمي برياضيات سنغافورة؟ تحصل سنغافورة علن المركز الأول في اختبارات التيمز TIMSS لتوجهات التحصيل في

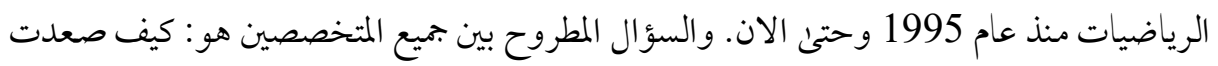

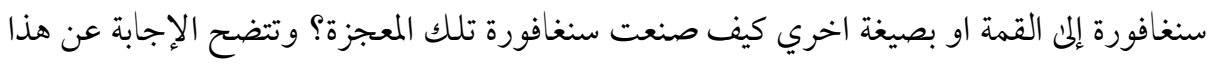

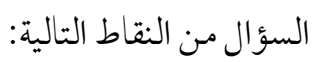

1- تؤكد مناهج رياضيات سنغافورة علن تنمية الحس العددي السريع والمهارات العقلية الرياضية والفهم العميق للقيمة المكانية.

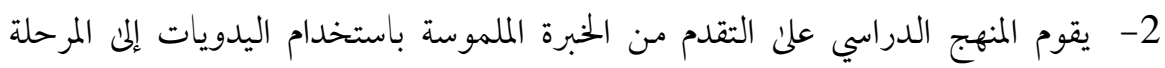

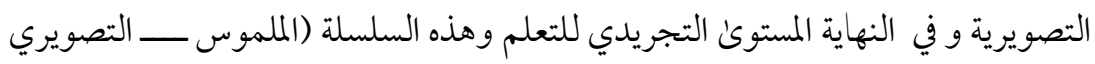
ـ المجرد) تمنح التلاميذ الفهم الجيد للمفاهيم والعلاقات الرياضية الأساسية قبل البدء في لئي

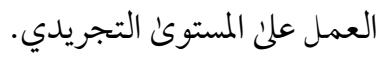

3- ؤكد مناهج رياضيات سنغافورة علن استخدام نموذج الشرائط البصرية لحل المشكلات

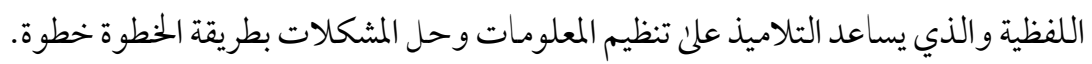

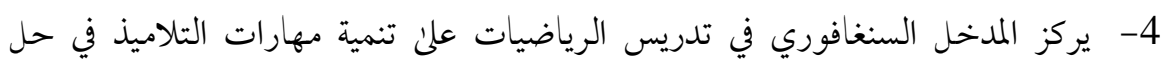

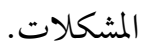
وتشير استيبك (Stipek, 2010, 2) إلم أسباب الاهتحام العلمي بمناهج الرياضيات في

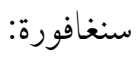
1. يحرز التلاميذ السنغافوريين بالصفين الرابع والثامن المركز الأول في اختبارات التيمز للرياضيات والعلوم منذ عام 1995 متفوقين علن تلاميذ أمريكا وباقي الدول في العالم. 
2. أشار تقرير الهيئة الاستشارية الوطنية للرياضيات (2007) إلى الأهمية البالغة لتنمية الكفاءة

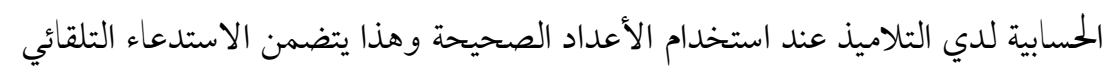

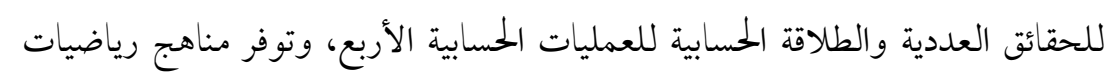

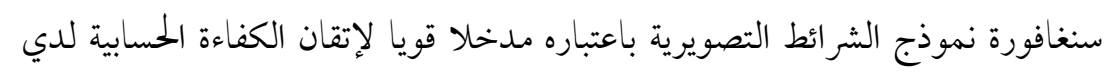

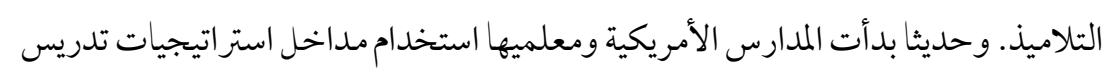
الرياضيات في سنغافورة (Clark,2008)

ما مر احل تطور مناهج الرياضيات في سنغافورة عبر السنوات؟ بعد أن حصلت سنغافورة عام 1984 علن المركز (16) من بين (26) دولة في الدراسة الثانية

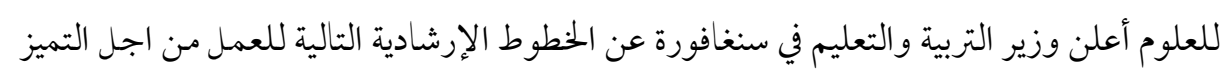

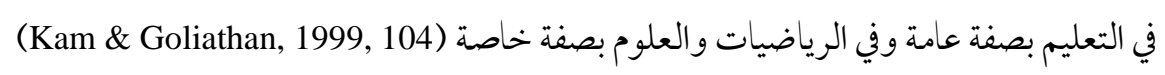

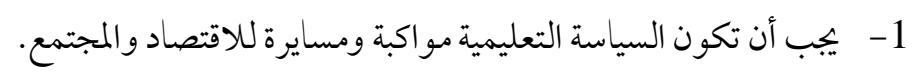

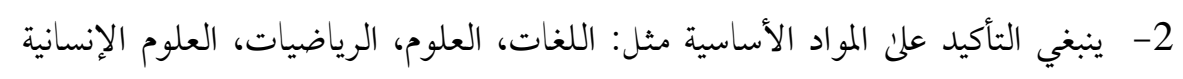

$$
\text { لتشجيع التفكير المنطقي والتعلم مدئ الحياة. }
$$

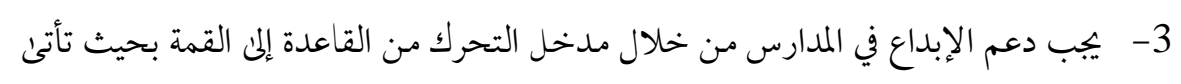

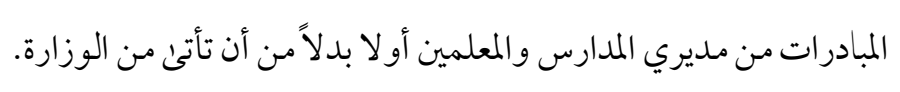

فقد كان محتوى الكتب الدراسية في مدارس سنغافورة يركز علن المهارات الحسابية، والقليل

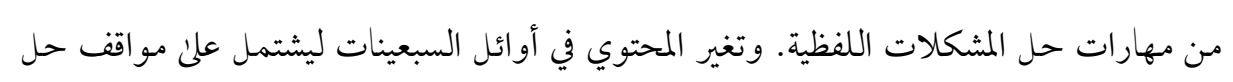

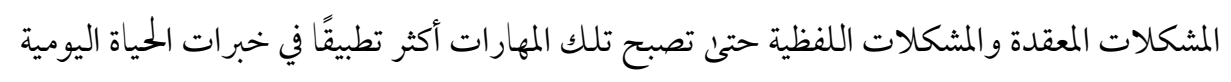

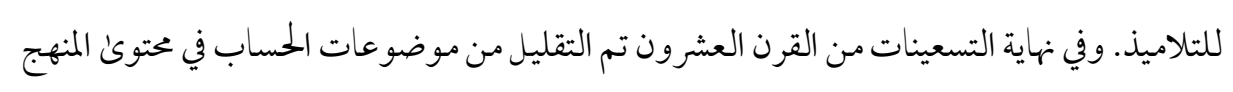

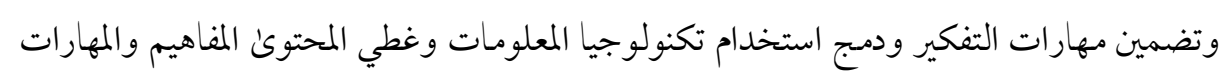
التي كانت تعتبر غير أساسية في الموضوعات المدرسية، من خلال الاعتماد علن قليل من التذكر والتركيز 
علن التفاصيل التقنية بدلاً من التركيز علن الفهم التصوري المجرد، حيث كانت الرياضيات مادة غير ذات صلة بممارسة العالم الحقيقي، والمحتوئ الرياضي كان صعبا جدًا وبجردا.

وتراجع سنغافورة سياستها التعليمية باستمرار للتأكد من ان أهدافها تتحقق وتسير في الطريق المرسوم لها. ونظرا لان الهدف من التعليم في سنغافورة هو إكساب الصغار المهارات اللازمة لكسب العيش، وتكوين قيم أخلاقية صحيحة، فان التلاميذ يجب ان يكونو اقادرون على تحمل المسئولية عندما يصبحو اكبارًا كما يكونون مو اطنين صالحين مخلصين. وتشجع عملية التدريس كل طفل علن التحدث و التعبير بحرية وتساعدهم علن زيادة إمكاناتهم. (Kam \& Goliathan, 1999, 100). وبالتالي هدفت التغييرات في مناهج التعليم في سنغافورة إلى عدم التركيز علن موضوعات المحتوئ الدراسي حيث تم تخفيض المحتون فاشتمل فقط علن المفاهيم غير الأساسية التي يمكن استرجاعها بسهولة وركز المحتون فقط علن التفاصيل الفنية بدلاً من الفهم التصوري المجردو المحتوى الذي لا علاقة له بممارسات العالم الحقيقي (Fall,2009). ( ) ( )

وكان تعليم الرياضيات في سنغافورة في السبعينات يؤكد علي أهمية تعلم المهارات الرياضية الأساسية. وشهدت الثخانينات والتسعينات ظهور معيار حل المشكلات في المعايير الوطنية والدولية، وأكد المجلس القومي لمعلمي الرياضيات (NCTM,2000) علن مركزية مهارات حل المشكلات في Clark, منهج الرياضيات وانتقل التركيز في تدريس الرياضيات الي حل المشكلات في عام 2006 2009, 2 ... ونتيجة لذلك راجعت سنغافورة مناهجها مرة أخرى و اكدت علن تنمية المفاهيم الرياضية، وتعزيز القدرة على تطبيقها في مو اقف حل المشكلات (Fall,2009).

ما جوانب الاختلاف بين مناهج الرياضيات التقليدية ومناهج الرياضيات في سنغافورة؟ يركن بيسك (Bisk,2010,1) أن منهج الرياضيات في سنغافورة يختلف عن منهج الرياضيات

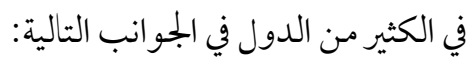


1. عدد موضو عات عحتوي المنهج الدراسي أقل ويتم تدريسها بعمق كبير من خلال اتاحة وقت

$$
\text { أكثر لدراسة كل موضوع مع تأكيد كبير علن الإتقان. }
$$

2. كثير من المثكلات الرياضية متعددة الخطوات ويتطلب حل المشكلات استخدام الإنفام مفاهيم

$$
\text { رياضييه متعددة مع تنوع كبير في المشكلات اللفظية. }
$$

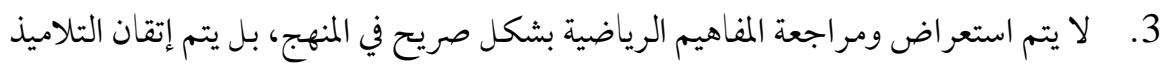

$$
\text { للمفاهيم عندما يدرسوها فقط. }
$$

4. يوجد مستوكن مرتفع من التوقعات ومخرجات التعلم المستهلفة من التلاميذ ضمن المنهج.

$$
\text { 5. مفاهيم الاحتمال غير متضمنة في منهج الصف الثامن. }
$$

ويرئ كلارك (Clark,2010,9) أن محتوي الكتب الدراسية في سنغافورة يبنى علن الفهم

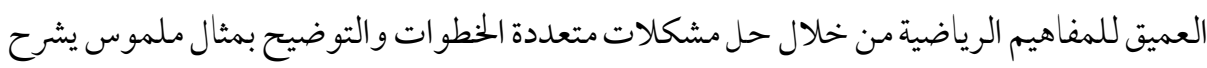

\begin{tabular}{|c|c|}
\hline $\begin{array}{l}\text { رياضيات سنغافورة } \\
\text { Singapore math }\end{array}$ & $\begin{array}{l}\text { الرياضيات الثقليدية } \\
\text { Traditional math }\end{array}$ \\
\hline 1 - تركز علن التفكير الناقدمن خلال المفاهيم. & 1- تركز علن ممارسة الأداء. \\
\hline 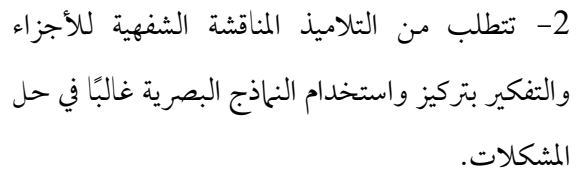 & 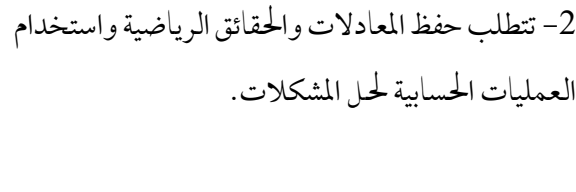 \\
\hline 3- تركز علن مفهوم واحد في كل مرة علن حدة ومفاهيم & بـ باستمرار. بهدف إلى دمج المفاهيم المتعلمة سابقًا مع المفاهيم \\
\hline
\end{tabular}
كيفية استخدام المفاهيم المجردة في حل المشكلات بأبعادها المختلفة. ويشير (Fall,2010) إلنى الاختلافات الأساسية بين الرياضيات التقليدية والرياضيات السنغافورية في الجلدول التالي:

$$
\text { جدول (1) الاختالافات الأساسية بين الرياضيات التقليدية والرياضيات السنغافورية }
$$

وتتمثل الاختلافات الكبيرة بين المدخل المستخدم في تعليم الرياضيات في سنغافورة والمداخل

$$
\text { الأمريكية التقليدية في التدريس فيما يلي: }
$$

http://dx.doi.org/10.29009/ijres.4.3.1 
1. لا توجد طريقة واحدة لتدريس الرياضيات في الولايات المتحدة الأمريكية حيث ان معظم القرارات المرتبطة بالمنهج الدراسي تتخذ علن المستوئ المحلئ أو الولاية (لامركزية التعليم). أما في سنغافورة فإن وزارة التربية والتعليم السنغافورية هي التي تقرر ما الذي سيتم تدريسه علن مستوى الدولة (مركزية التعليم) . ويتميز مدخل التدريس في سنغافورة بها يلي: - - - التأكيد علن مفهوم الجزء- الكل - الاهتمام بالرياضيات العقلية. - التو اصل من خلال نشاط انظر وتحدث لبناء الفهم للغة الرياضية. - استخدام غخططات القيمة المكانية. - الاتصال بالصور، والكلمات والأعداد. 2. المعلمون السنغافوريين من أكثر أصحاب المهن الذين يجظون في بلدهم باحترام التلاميذ

$$
\text { واولياء الامور. }
$$

3. يجصل المعلم السنغافوري علن تدريب أكثر ولديه وقت للدراسة أكثر مقارنة بمعظم المعلمون

$$
\text { الأمريكان كما يعمل المعلم السنغافوري ساعات أطول بمعدل (10 - 12) ساعة يوميًا. }
$$$$
\text { 4. يوجد دعم ومساندة كبيرة من الوالدين واولياء الامور للتعليم في سنغافورة. }
$$$$
\text { 5. تحتوي معظم فصول المدارس الابتدائية في سنغافورة على (30- 40) تلميذ. }
$$$$
\text { 6. زمن حصة الرياضيات في مدارس سنغافورة } 60 \text { دقيقة يوميًا. }
$$

\section{ما أبرز نقاط القوة في رياضيات سنغافورة؟}

يركن كل من (Clark,2008)، (Chen, et.al, 2010) أن نقاط القوة في مناهج الرياضيات

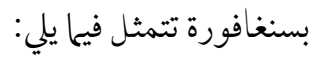
1- تنمية الحس العددي القوكا و المهارات الرياضية العقلية والفهم العميق للقيمة المكانية. 
2- الاعتلاد علن التحرك اثناء التعلم من المحسوس الي التصويري الي المجرد. ففي مرحلة التعلم

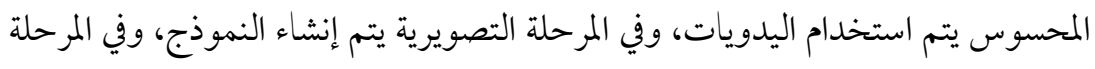

$$
\text { المجردة يتم استخدام الحساب الذهني. }
$$

3- تغطية موضو عات أقل عمقا، ولكن من خلال دراسة مفصلة حتى الإتقان.

4- استخدام استراتيجيات حل المشكلات الخاصة بالمدخل السنغافوري في التدريس.

$$
\text { 5- اعتبار حل المشكلات هدفا رئيسا لتعليم الرياضيات في سنغافورة. }
$$

ويؤكد منهج الرياضيات في سنغافورة بقوة علن مهارات حل المشكلات، وعلن بناء المفاهيم

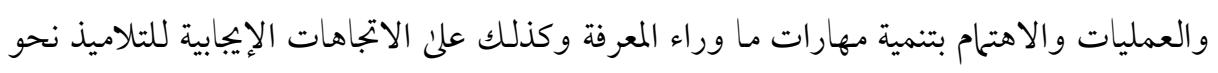

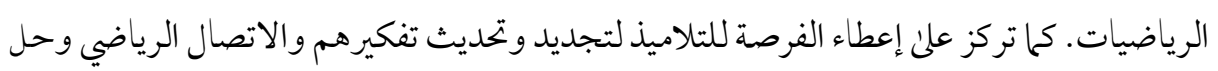

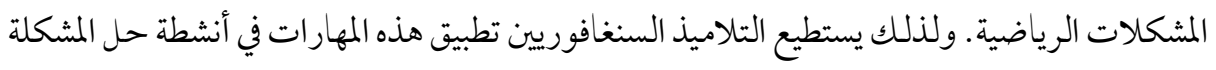
المختلفة. وتتجمع العناصر السابقة في مضلع حل المشكلة الحماسي الذي جعل من حل المشكلات مركزًا له. ويزداد تأكيد منهج رياضيات سنغافورة علن مدخل حل المشكلة باعتباره أحد اهم مفاتيح نجاحها.

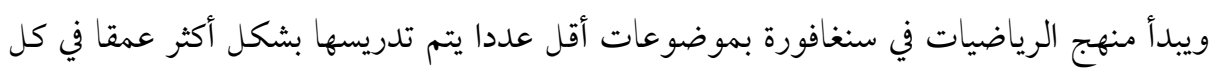
صف.

ويشير كل من كام وجوناثان (Kam \& Goliathan) إلى نقاط القوة التالية في منهج الرياضيات

في سنغافورة بالمرحلة الابتدائية كما يلي:

المنهج متماسك ومترابط بدرجة كبيرة ويتم تدريسه بطريقة الخطوة خطوة والتي تبنى علن معارف ومهارات التلاميذ السابقة.

1. المنهج يتبع سلسلة التحرك: الملموس التصويري المجرد الذي يقوم علن نظرية برونر.

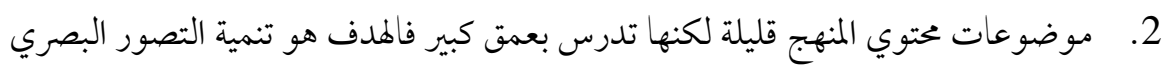
والإتقان.

$$
\text { 3. حل المشكلات هو جوهر أو بؤرة منهج الرياضيات. }
$$

http://dx.doi.org/10.29009/ijres.4.3.1 
4. تعزيز القيمة المكانية، والرياضيات العقلية من خلال حل المشكلات.

5. تعكس ثقافة تعليم الرياضيات في المرحلة الابتدائية بسنغافورة تطوير فهم التلاميذ للحقائق العددية، والحس العددي، والأنماط، والتصور البصري، والتو اصل الرياضي. 6. تتعلق الاستراتيجيات التعليمية المستخدمة في منهج الرياضيات السنغافوري بالمرحلة الابتدائية بالقيمة المكانية والرياضيات العقلية والحساب والمودل السنغافوري.

ما أسباب أهمية التركيز على حل المشكلات في سنغافورة؟ حل المشكلات هو لب وجوهر منهج الرياضيات في سنغافورة حيث يدرس التلاميذ في المرحلة الابتدائية مدخل المودل السنغافوري التصويري لحل المشكلات اللفظية التي تُدرس في كثير من البلاد في المناهج في وقت لاحق باستخدام الرموز الجبرية المجردة (Lee \& Ng,2011,82). و إن ما يثير الانتباه أن منهج رياضيات سنغافورة القديم الذي تم تدريسه في الثمانينات لم يكن يؤكد علن حل المشكلات وظل هكذا حتى عام (1991). وفي عام (1992م) بدأت سنغافورة في التأكيد على حل (Clark,2009,1) المشكلات في منهجها

وتوجد ثلاثة أهداف لتعليم التلاميذ في سنغافورة حل المشكلات سواء حسابيًا وجبريًا: (Cai,

وهي مساعدة التلاميذ على تحقيق فهم عميق للعلاقات الكمية من خلال تمثيلها حسابيًا وجبريًا على حد سواء وتوجيه التلاميذ لاكتشاف أوجه الشبه والاختلاف بين الطريقة الحسابية والجبرية ولذلك يمكنهم الانتقال السلس من التفكير الحسابي للتفكير الجبري وتنمية مهارات تفكير التلاميذ بالإضافة للمرونة في استخدام الطرق الملائمة لحل المشكلات. ويرئ الكثير من المربين السنغافوريين (Clark, 2009, 5) أن بناء الاستجابة الصحيحة اثناء حل المشكلات يتطلب من التلاميذ القدرة علن قراءة الفقرات المعقدة في المشكلة بمستوي معقول والقدرة علن توصيل أفكار التلاميذ من خلال عرض وبيان كيف وصلو اللإجابة وتبريرهم للسبب. 
وذكرت وزارة التربية والتعليم السنغافورية(Clark,2009,1 ) أن حل المشكلات هو الهدف الأساسي لتعليم الرياضيات والعلوم في سنغافورة لأن حل المشكلات الرياضية هو مركز أو بؤرة تعليم

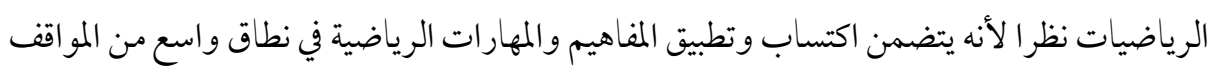
التي تتضمن مشكلات العالر الحقيقي، والمشكلات مفتوحة النهاية وغير الروتينية تعتمد تنمية القدرة على حل المشكلات الرياضية علن خمس عناصر مترابطة، وهي: المفاهيم، والمهارات، العمليات،

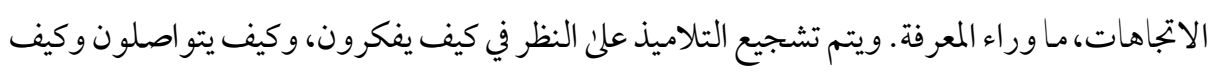
يحلون المشكلات. لذا يمكنهم تطبيق مهار اتهم في مشكلات لاحقة بعد خروجهم من المدرسة. وركزت الجهود الأخيرة لوزارة التربية والتعليم السنغافورية علن زيادة تو اصل التلاميذ وعمليات ما وراء المعرفة

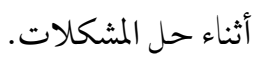

ولقد تأسست كتب ومنهج رياضيات سنغافورة علن استراتيجيات جورج بوليا الواردة في كتابه لتدريس استراتيجيات معينة للتلاميذ لمساعدتهم علن حل المشكلة مثل: استراتيجية البحث عن نمط، رسم صورة، تبسيط المشكلة، العمل للخلف. وكل هذه الاستراتيجيات متضمنة في الكتب الأمريكية حيث يتعلم التلاميذ في أمريكا البحث عن نمط ثم تقدم لهم المشكلات التي تُحل بهذه الطريقة. أما في سنغافورة يتم تشجيع التلاميذ علن التفكير في الاستراتيجية التي ستكون أفضل لحل لحل مشكلة معينة، حيث يتم تقديم عدد من الاستراتيجيات للتلاميذ ثم تطرح عليهم العديد من المشكلات غير الروتينية المطلوب حلها باستخدام تلك الاستراتيجيات. (Clark, 2009, 4) وعلى الرغم من زيادة التأكيد علن حل المشكلات في أمريكا فقد واصل تلاميذ سنغافورة تفوقهم، فما السبب؟ توجد خمسة أسباب رئيسية تؤدى للاختلاف في التحصيل الرياضي بين تلاميذ سنغافورة وتلاميذ أمريكا ويشير إليها كلارك (Clark, 2009, 2) كما يلي: 1. حل المشكلات متضمن في الكتب الدراسية السنغافورية وليس نشاطا منفصلا لكنه مركز كل 
2. يتعامل تلاميذ سنغافورة مع مشكلات أكثر تعقيدًا من تلك المشكلات الموجودة في الكتب

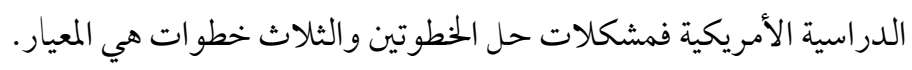

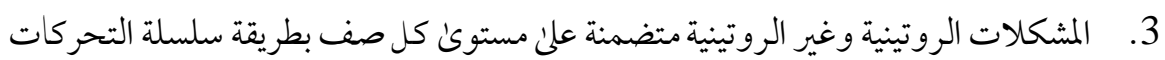

$$
\text { (من التعلم المحسوس-الي التعلم التصويري- الي التعلم المجرد). }
$$

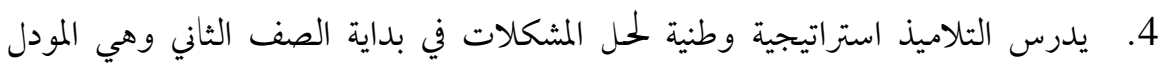

$$
\text { 6- يتم دعم التجاهات التلاميذ نحو التعلم من المعلمين واولياء الامور. }
$$

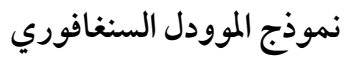

يدور النموذج السنغافوري لتعليم الرياضيات Bar Model حول النقاط التالية:

$$
\text { 2-1 - التفكير في الأعداد. }
$$

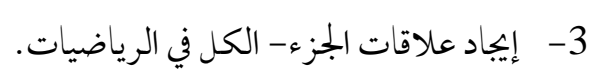

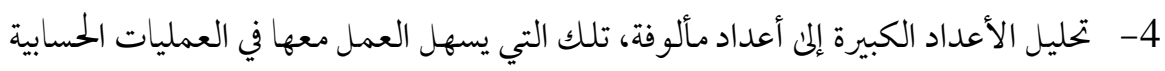

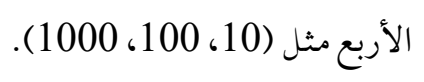

5- الرياضيات العقلية ججال مهم في رياضيات سنغافورة. 


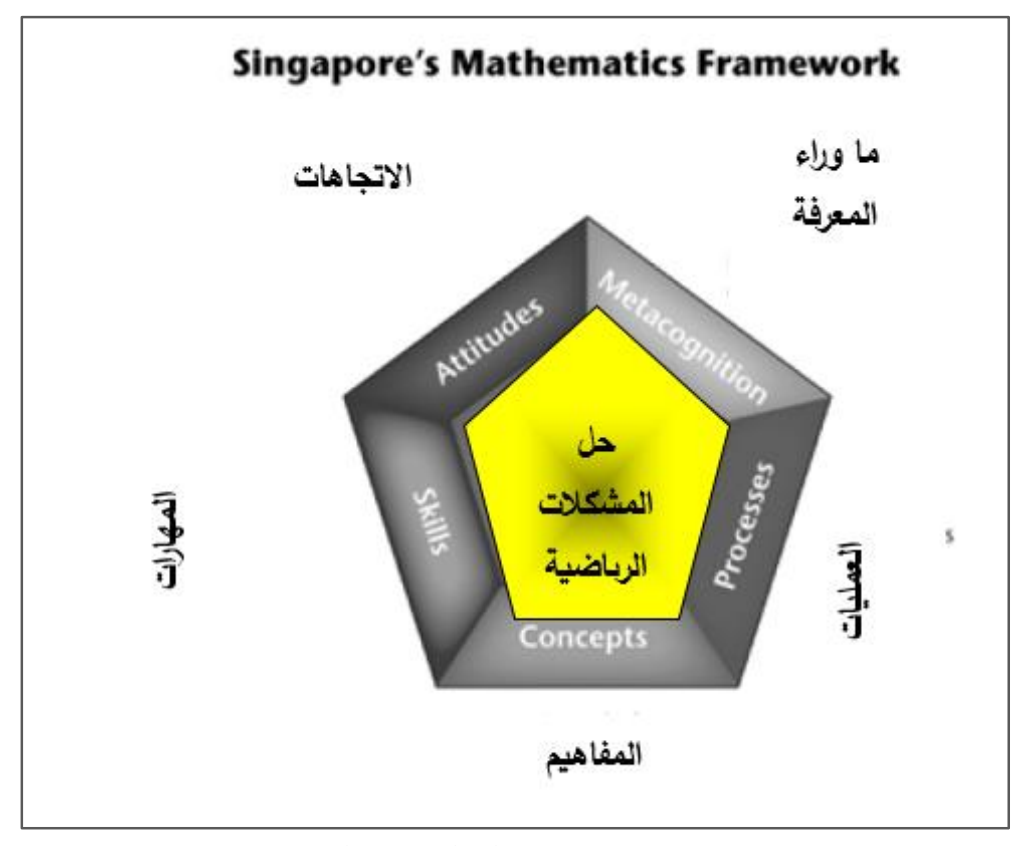

$$
\text { شكل (1) النموذج الرياضيات في سنغافورة }
$$

أهداف نموذج المودل السنغافوري

يستخدم نموذج المودل السنغافوري في حل المشكلات اللفظية حيث يقوم التلميذ بتحديد المعلومات الرئيسية في المشكلة في نموذج تصويري يشتمل علن وحدات في شكل مستطيلات ويتم

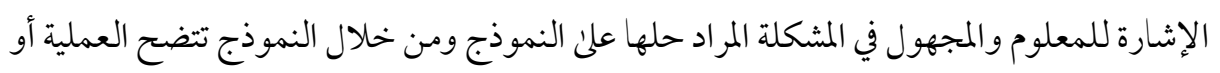
Bisk \& العمليات الحسابية الواجب استخدامها ويتم حل المشكلة. ويشير كل من بيسك وهوجان المنان (Hogan, 2007)

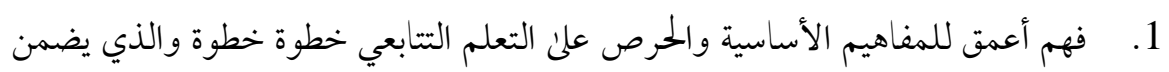
النجاح. 2. تفعيل التحركات اثناء سلسلة التعليم من التعلم المحسوس إنى التعلم التصويري إلى التعلم المجرد. 
3. الاستخدام الثابت المنتظم للنماذج البصرية اثناء الحلل التي تدعم تنمية التصور البصري لدي

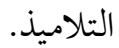

4. التأكيد علن المودل السنغافوري، والرياضيات العقلية، والاستراتيجيات التعليمية الأساسية

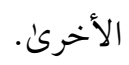

\section{كيف يسهم المودل السنغافوري في تنمية مهارات حل المشكلات اللفظية؟}

يبين كرون (Kron,2009) أن المودل السنغافوري يسهم في تنمية مهارات حل المشكلات

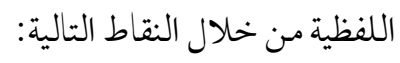

1. وحدات المودل السنغافوري تبين العلاقة بين أجزاء ومكونات كل مشكلة لفظية.

2. النماذج المنشأة تحدد المعلومات المعطاة والكمية أو الكميات المجهولة أيضًا والتي هي المفهوم

$$
\text { الرئيسي للتفكير الجبري. }
$$

3. المودل السنغافوري يشجع التلاميذ علن اكتشاف المفاهيم والعلاقات في مركز مشكلة 
مقياس تقدير الأداء في حل المثكلات وفقًا للمودل السنغافوري:

يقدم تشار (Char,2000) مقياس تقدير الأداء التالي الذي يمكن استخدامه في حل المشكلات

وفقًا للمودل السنغافوري:

\begin{tabular}{|c|c|c|c|c|}
\hline 4 & 3 & 2 & 1 & قواعد المودل السنغافوري \\
\hline & & & & 1 - قراءة المشكلة كلها. \\
\hline & & & & 2- تحديد حول من، وما تدور حوله المشكلة. \\
\hline & & & & 3- قراءة المشكلة مرة أخرى واستخدام المعلومات الضرورية في رسم \\
\hline & & & & 4- تحديد السؤال وتوضيحه علن وحدات النموذج. \\
\hline & & & & 5- إجراء العمليات الحسابية وحل المشكلة بصورة صحيحة. \\
\hline & & & & 6- كتابة الإجابة في جملة كاملة. \\
\hline
\end{tabular}

(4) يكمل الخطوة بشكل منتظم وثابت ومستقل. (3) يكمل الخطوة غالبًا على مستوكن مستقل. (2) يجتاج إلى مساعدة في الخطوة. (1) لا يحاول ولا يريد المساعدة بالخطوة.

المثكلات التي لا يصلح معها المودل السنغافوري:

يرى كرون (Kron,2009) أنه بعض المشكلات الرياضية لا يصلح معها المودل السنغافوري ومنها: 1 - مشكلات الفحص والتخمين. 2- المشكلات التي لها أكثر من إجابة صحيحة ومنها مشكلة عمل قائمة، والمشكلات المركبة، واستخدم كل رقم مرة واحدة للحصول علئ (24). 3- - مشكلات إيجاد النمط. 


$$
\text { 5- - مشكلات رسم الصورة، كانعكاس لصورة ما. }
$$

إذا كان العدد في المربع نتيجة الأعداد في كلا الدائرتين. أوجد الأعداد في كل دائرة:

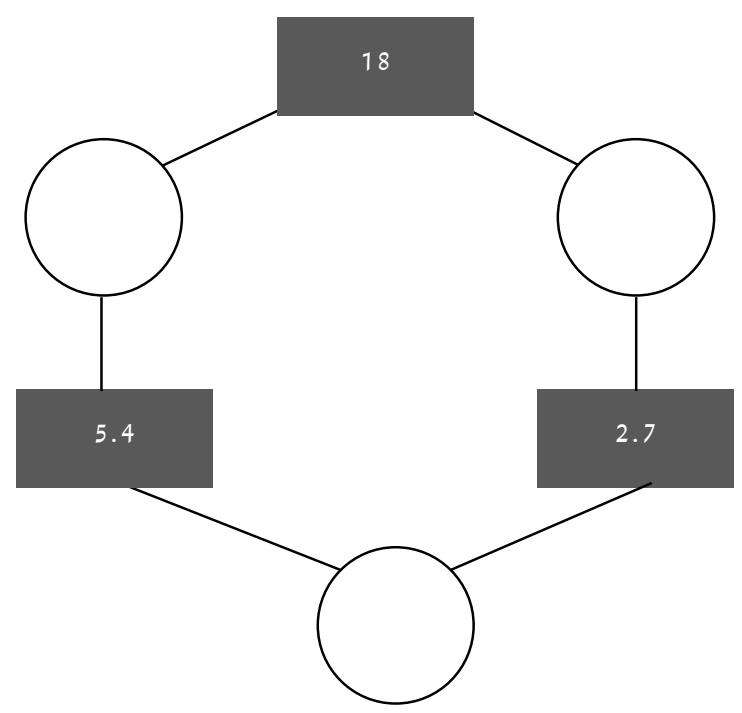

Chen, et.al, ويمكن استخدام المودل السنغافوري في حل 80 ٪ من المشكلات تقريبًا. (2010) ، و ذلك بدلاً من حل المشكلات اللفظية للجمع بطريقة ما والمشكلات اللفظية للكسر العشري (Stipek, 2011) بطريقة ثانية وهكذا. ماذا قال المعلمون عن المودل السنغافوري؟ يشير بيسك (Bisk,2010,6) إلى تعليقات المعلمين التالية للمعلمين حول رياضيات سنغافورة

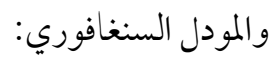
1- لم أدرك أنىل لمر أكن أفهم الرياضيات حتى تعلمت دراسة الرياضيات من الكتب الدراسية سنغافورة.

\section{http://dx.doi.org/10.29009/ijres.4.3.1}


2- موضوعات الرياضيات في سنغافورة تُدرس حتى الإتقان. موضوعات قليلة تُدرس بعمق كبير.

3- المر اجعة عادة ضمن محتوئ الموضوع الجديد أو خلال استخدام المشكلات اللفظية. 4- موضوعات الرياضيات في سنغافورة تؤكد علنى المنطق والتصور البصري 5- يُتوقع من التلاميذ في سنغافورة إتقان الحساب الأساسي في الصفوف المبكرة. 6- يتعلم التلاميذ في سنغافورة لماذا يستخدمون صيخ وقوانين معينة بدلاً من تعلم فقط كيفية تطبيق القوانين.

7- السمة المميزة في مناهج الرياضيات في سنغافورة أن البرنامج يشجع التلاميذ علن التفكير

$$
\text { العملي، وتعزيز تواصل الأفكار الرياضية }
$$

8- تشتمل مناهج الرياضيات في سنغافورة على عنصر قون وهو حل المشكلات. المشكلات

$$
\text { ليست فقط تمارين حسابية متضمنة في المحتوى البسيط }
$$

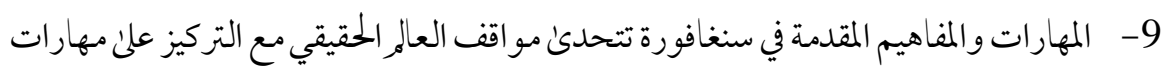

$$
\text { التفكير، كما أن الكتب الدراسية بسيطة في لغتها. }
$$

10- التلاميذ يعرفون الحقائق العددية. خاصة أولئك التلاميذ الذين ليس لديهم صعوبات كبيرة

$$
\text { مع المشكلات المعقدة. }
$$

11- بسبب هذا النموذج البسيط يكون التلميذ قادرًا على الإبقاء علن تركيزه علئ هدف الدرس.

$$
\text { 12- برنامج رياضيات سنغافورة يشجع التلاميذ لفهم ما وراء الأساسيات و التفكير }
$$

ومن تعليقات المعلمين التي ذكرها كل من فورستن وستيبك: (Forsten\&Stepic 2010,2)

$$
\begin{aligned}
& \text { 1- المودل السنغافوري يُحسن من فهم التلاميذ } \\
& \text { 2- المودل السنغافوري طريقة ممتازة لتدريس المعلومات } \\
& \text { وتذكر استيبك (Stepik,2010,2) مـا يلي: }
\end{aligned}
$$


1- المودل السنغافوري هو استراتيجية بصرية رائعة وجديرة بالملاحظة من السهل تكاملها مع

$$
\text { أي برنامج رياضيات. }
$$

2- المودل السنغافوري طريقة قذفت بجزيرة صغيرة لقمة دول العالم في تحصيل الرياضيات وساعد التلاميذ السنغافوريين لتحسين مهار اتهم في التفكير الناقد، ولغة الرياضيات، والجبر،

$$
\text { وحل المشكلات الرياضية اللفظية. }
$$

وتشير استبيك أيضا (Stipek, 2010,4) إلى ما قاله عددمن المعلمين عن المودل السنغافوري:

$$
\text { 1- مذا يجب أن يكون عنصرًا في تعليمنا للرياضيات. }
$$

2- ستغير من تدريسك للرياضيات بعد الاطلاع علن المودل السنغافوري.

3- النموذج السنغافورية سيغير تمامًا من طريقة تفاعل التلاميذ مع المشكلات اللفظية

4- المودل السنغافوري يساعد التلاميذ في أن يصبحو امترقبين لحل المشكلات و الذين يمتلكون

القدرة علن النجاح في حلها مبكرًا وبشكل متكرر. (Stepik, 2011)

مثال: حل مشكله رياضية بالنموذج السنغافوري

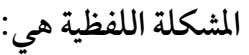

يوجد في مزرعة محمد (19) أوزه ودجاجة وبطة، وكان عدد الدجاجات يزيد عن عدد الأوز

$$
\text { بمقدار (3) وعدد البط يقل عن عدد الأوز بمقدار (2). فكم يكون عدد البط؟ }
$$

أحد التلاميذ قد يختار العدد (19) علئ المعداد، ويخصص الرقم (1) للبط، والرقم (3) للأوز، والرقم (6) للدجاجات، ثم يضيف التلميذ لكل صف على المعداد وحدات حتى يصل إلى الـعدد (19) الذي كان قد استخدمه في البداية. وقد يستخدم تلميذ آخر استراتيجية العمل للخلف فئلفإذا أخذا الرقم (5) للدجاجات، والرقم (2) للأوز، سيبقى الرقم (3) مقادير متساوية. بعد ذلك سيبقى الرقم (12) 
علن المعداد وهذا يعنى أن يكون للكل (4)، لذلك تكون النتيجة (4) بطات. وهذا يدل علن ان تشجيع

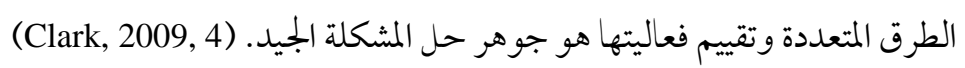
سلسلة التحرك من التعلم المحسوس-الي التعلم التصويري- الي التعلم المجرد (CPA): يتعلم التلاميذ الرياضيات في سنغافورة علن مر احل متعددة (Kheong,2009,2):

المرحلة الحسية: وفي هذه المرحلة يتم استخدام المحسوسات حيث تستخدم اليدويات مثل العدادات، أقر اص الأعداد، وخططات القيمة المكانية. المرحلة التصويرية: وفي هذه المرحلة يتم استخدام الصور التي تمثل الأعداد عند حل المشكلات. المرحلة المجردة: وفي هذه المرحلة يتم استخدام قيم الرموز العددية ويؤكد برونر علن التمثيل المحسوس والذي يتوافق

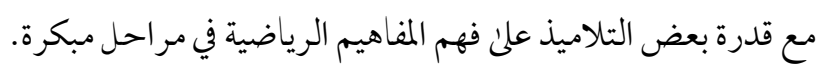

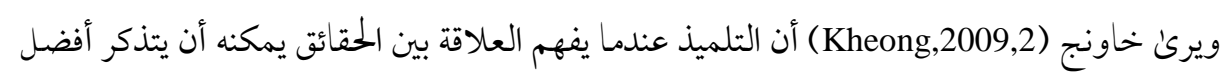

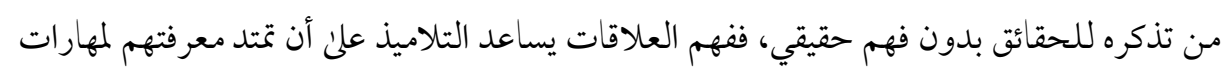

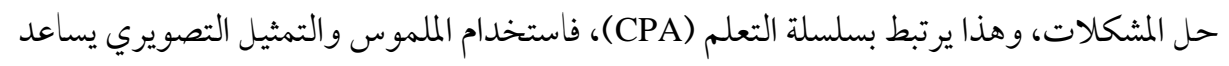

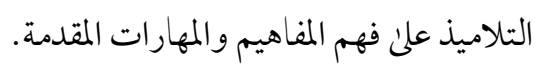

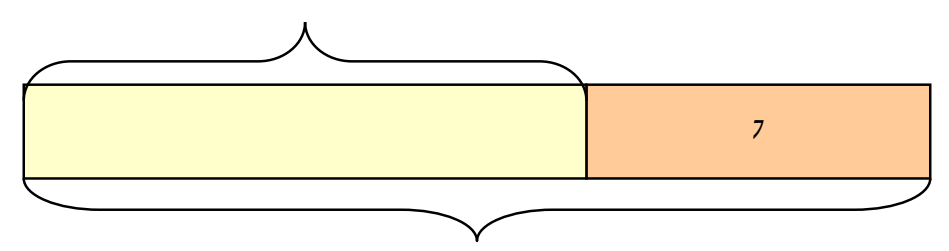

$$
\text { عدد بيض الدجاج = } 20 \text { - }=73 \text { دجاجة }
$$

http://dx.doi.org/10.29009/ijres.4.3.1 
ويستخدم المودل السنغافوري مع المشكلات اللفظية البسيطة في الصف الثاني، حيث يقسم التلميذ المستطيل الكبير إلى جزئين لمو اقف الطرح، فمثلاً: يو جد (20) بيضة لكل من البط والدجاج في

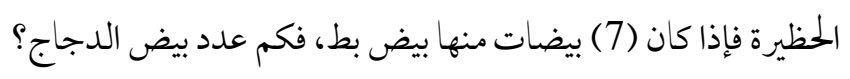
كما يدرس التلاميذ في سنغافورة نماذج أخرى تتضمن الضرب والقسمة البسيطة، والتي تزداد تعقيدًا في الصف الخامس.

ويطبق التلاميذ المودل السنغافوري علي مشكلات بسيطة وسهلة في الصف الثالث مثل: باع رجل (230) بالونه في صباح اليوم الأول من أيام عيد الأضحن، وفي اليوم الثاني باع (86)

$$
\text { بالونه أخرىن. فما عدد البالونات التي باعها الرجل في اليومين؟ }
$$

وفي الصفين الرابع والخامس يطبق التلاميذ المودل السنغافوري اثناء حل مشكلات رياضية أكثر صعوبة ويتطلب حلها خطو ات متعددة، فالتلاميذ بعد استخدامهم للمودل السنغافوري في الصف الثالث في الضرب و القسمة، يكونون مستعدون لتطبيقه في حل مشكلات الكسور مثل: اشترئ سامي 42 تفاحة منهم (2/ 7 ) حمراء، وبقية التفاح خضراء اللون. فكم عدد التفاح الأخضر الذي اشتراه سامي؟

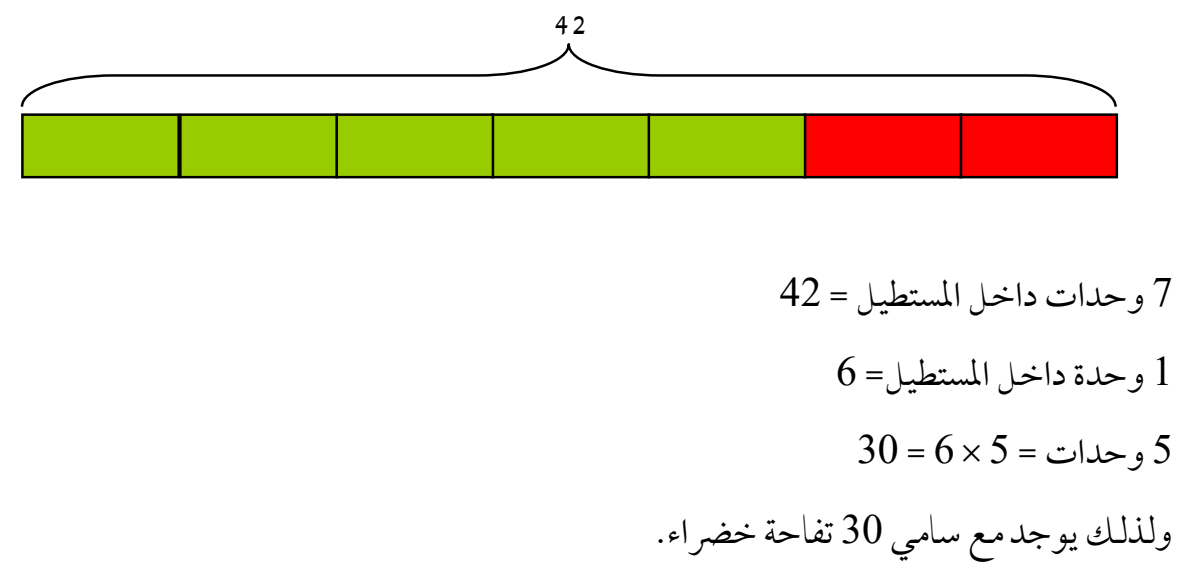

http://dx.doi.org/10.29009/ijres.4.3.1 
وفي الصف السادس يكون التلاميذ مستعدون لحل المشكلات الصعبة والمعقدة. مثل:

صرفت منى 20 ٪ من نقودها عند شر اء فستان، و أنفقت (2 ٪ 5) من المبلغ المتبقي عند شراء

كتاب، فتبقى معها 72 جنيه. فكم المبلغ الذي كانت تملكه في البداية؟(Hoven, \& Garelick, 2007)
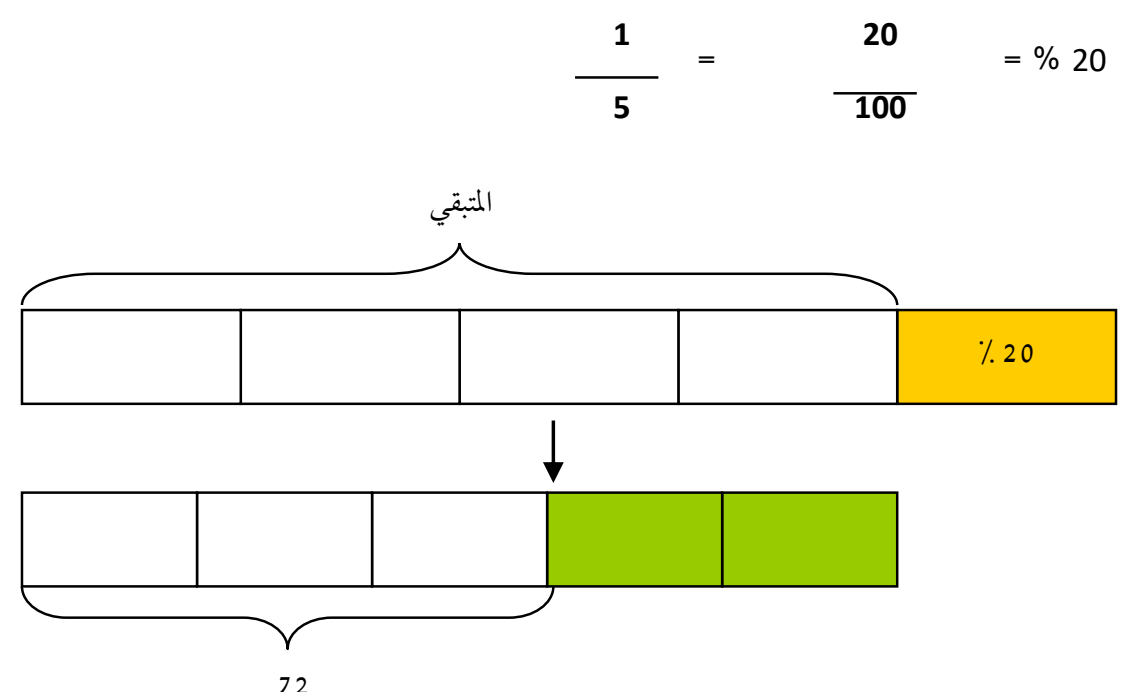

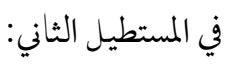

3 وحدات داخل المستطيل = 72

24 = 1

5 وحدات = $120=24$

وفي المستطيل الأعلى:

4 أجزاء داخل المستطيل = 120

10 جزء 10

50 أجزاء 50 = 50 
وبالسماح للتلاميذ بتحديد المعلوم والمجهول في المشكلة فإن المودل السنغافوري يضع التلاميذ في مرحلة التمثيل الجبري (Hoven, \& Garelick, 2007) والتحول الي الرموز ومن أمثلة ذلك:

نفرض أن المبلغ الذي كان مع منح في البداية = سل (وهو طول النموذج المستطيلي العلوي)

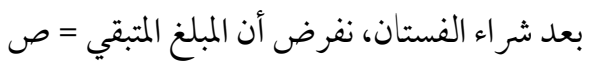

$$
\text { فحسب المستطيل الثاني: } 72 \text { جنيه }
$$

$$
\text { ويكون: ص =5 × } 5 \text { = } 120 \text { = } 120 \text { جنيه. }
$$

وحسب المستطيل الاول: المبلغ الذي أنفقته عند شراء الفستان = 0.20 س = $=\frac{1}{5}=$

$$
\begin{aligned}
& \text { ولذلك:ص = } \\
& \text { س } \frac{4}{5}=120 \\
& 30=\frac{120}{4}=\mu \frac{1}{5} \\
& \text { س = } 30 \text { × } 50 \text { = } 150 \text { جنيه. }
\end{aligned}
$$

وبالتالي فإنه من الشائع استخدام المودل السنغافوري في مواقف حل المشكلات في الصفين

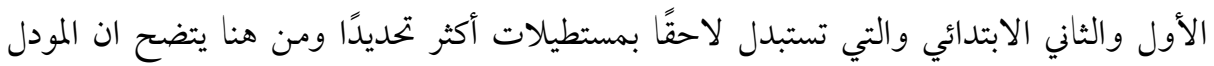

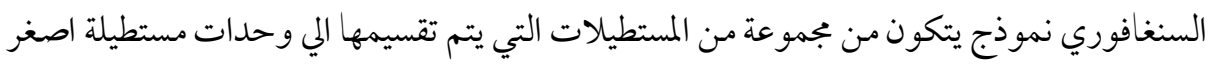

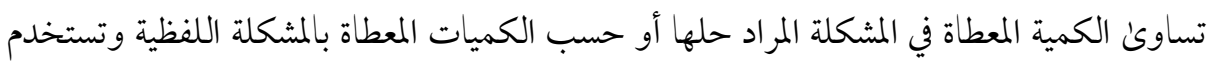

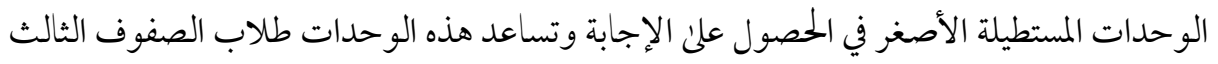


و الرابع للتعامل مع المشكلات اللفظية الجبرية بسهولة ويسر مع تجنب استخدام المعادلات الجبرية.

(Cai, Moyer, 2007, 5)

مثال:

ذهب أحمد لشراء (3) كجم من الجمبري، و كان معه (47) جنيه، وبعد شر ائه للجمبري تبقى معه 20

جنيه. أوجد تكلفة الكيلو جرام الواحد من الجمبري؟

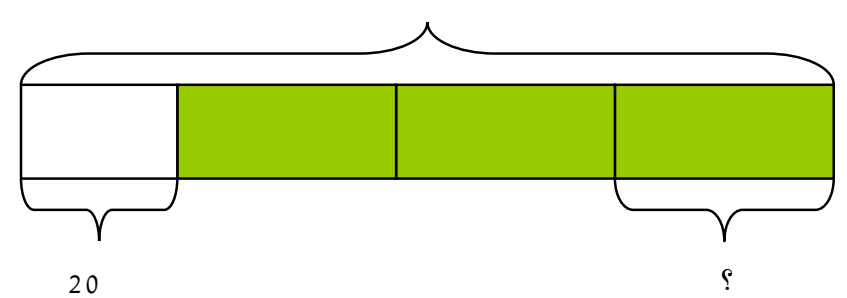

ويمكن الحل باستخدام المودل السنغافوري كما يلي: تكلفة الـ 3 كجم من الجمبري = 47 - 20 = 27 جنيه. وتكون تكلفة الكيلو جرام الواحد = 27 ؛ 3 = 9 جنيهات. اما باستخدام الجبر المعتاد فيكون الحلل أطول و أصعب علن النحو التالي: تتطلب المشكلة حل المعادلة الجبرية 3 س + 20 = 47، وهذا يمكن أن نراه مباشرة من خلالال الرسم التوضيحي السابق حيث تمثل الوحدة الصغيرة المستطيلة عدد الوحدات(س) والتي بدورها تمثل تكلفة كيلو جرام واحد من الجمبري. فيبدأ التلاميذ في تعلم ذلك في الصف الثاني وفي كل صف صف يضاف مستوكأ جديد من التعقيد، والعمليات، ويتعلم التلاميذ تثثل العلاقات المختلفة مثل: علاقة الجزء - الكل، وعلاقة المقارنة، وإن تعلم التلاميذ تمثيل وتصوير العلاقات ييعل الحل أسهل، ويبدأ التلاميذ بالمشكلات البسيطة لكن الهدف حلهم للمشكلات المعقدة. (Clark,2010,6) 
ومن المشكلات اللفظية التي يمكن حلها باستخدام نموذج الموودل السنغافوري في الصفوف المختلفة بالمرحلة الابتدائية (Clark,2010,10):

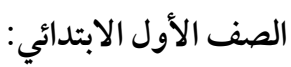
- سلة ليمون بها 3 ليمونات، 2 ليمونة لونها أصفر، والباقي ليمون أخضر. فكم عدد الليمون

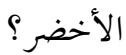
- في ملعب المدرسة 6 بنات، و 3 أو لاد يلعبون معهم. فكم عدد الأطفال الذين يلعبون معًا. الصف الثاني الابتدائي: - باعت إحدى المكتبات 27 كشكو لاً في الصباح، وباعت بعد الظهر 39 كشكو لاً. كم عدد الكشاكيل التي باعتها المكتبة؟ - مبك

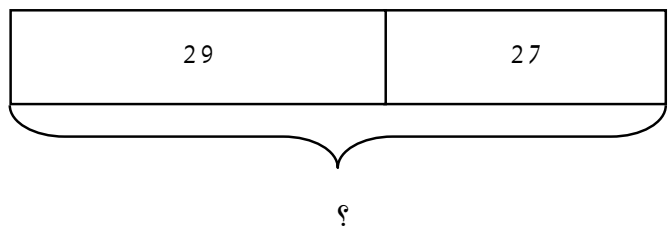

$$
27 \text { + } 27 \text { = } 66 \text { باعت المكتبة } 66 \text { كشكولاً. }
$$

- - حفظت نبيلة 365 كلمة في اللغة العربية في الصف الأول، وفي الصف الثاني حفظت 419

$$
\text { كلمة، فكم عدد الكلمات التي حفظتها نبيلة؟ }
$$

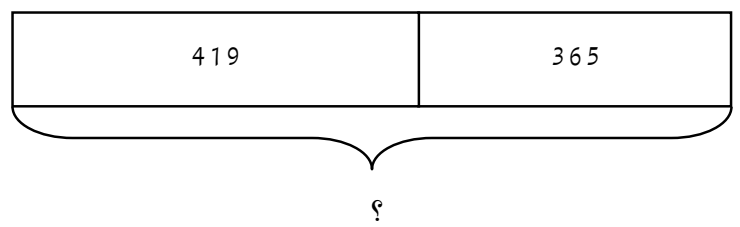

http://dx.doi.org/10.29009/ijres.4.3.1 
- - اشترت رشا 24 بيضة، أكلت 7 بيضات منها. فكم عدد البيض المتبقي؟

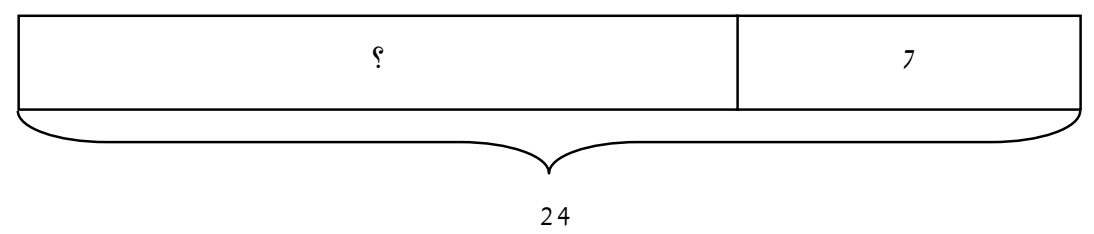

$$
24
$$

الفحص: 17 + 7 = 24 (إذن الإجابة صحيحة) الصف الثاني الابتدائي: مشكلة جزء - كل

باعت سوزان 75 صندوق فاكهة في اليوم الأول، وفي اليوم الثاني باعت 84. فكم عددصناديق الفاكهة

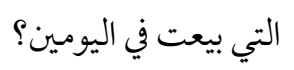

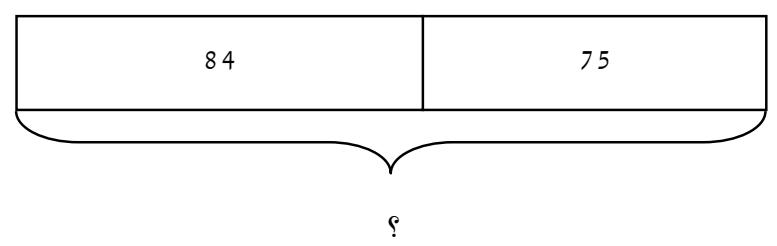

- - اشترت ياسمين كعكةة بـ 15 جنيه، وتبقلى معها 42 جنيه. فكم كان معها في البداية؟

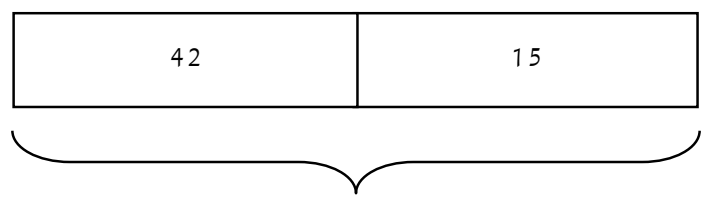

؟ 
الصف الثالث الابتدائي: مشكلة المقارنة

مع أمين 10 جنيهات، ومع إسلام مبلغ يزيد عنه بمقدار 2 جنيه. فكم المبلغ معها؟

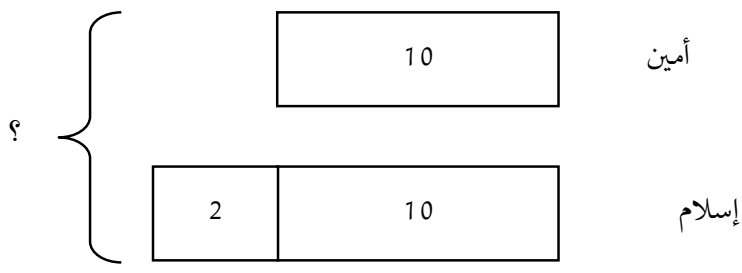

$$
22=2+10+10
$$

- اشترئ محمد 345 صندوق فاكهة، واشترئ أحمد ما يزيد عنه بمقدار 230 صندوقًا. فكم

عددصناديق الفاكهة التي اشتراها أحد؟

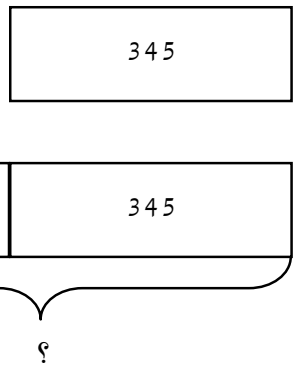

محمد

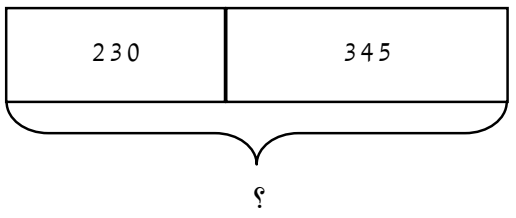

أمدا

- - اشترى سمير 110 زجاجة مياه. باع منها 28 زجاجة. فكم عدد الزجاجات المتبقية؟

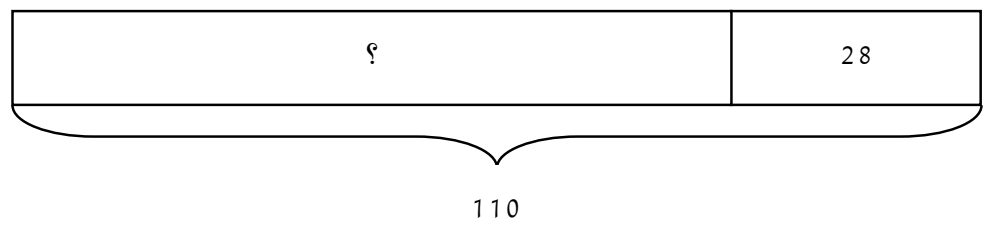

$82=28-110$

http://dx.doi.org/10.29009/ijres.4.3.1 
- قرأت هبة 749 صفحة. بينما قرأت هبة أقل منها بمقدار 324. فكم عدد الصفحات التي

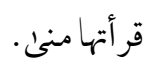

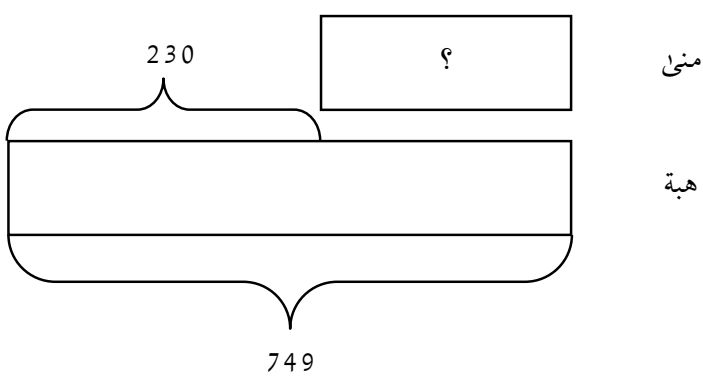

$$
425=230-749
$$

- مع أحمد 35 جنيه. ومع محمود 44 جنيه. فكم يزيد محمود عن أحمد؟

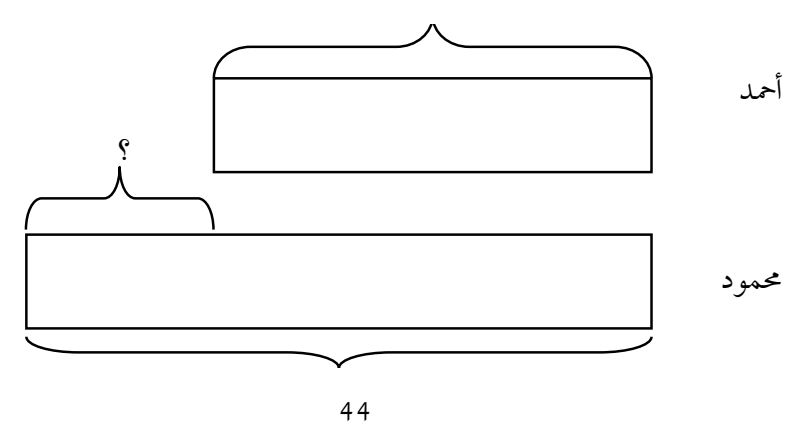

$$
9=35-44: \text { الحل }
$$




\section{Area model of multiplication نموذج المساحة لحل مشكلات الضرب}

يتم استخدام نموذج المساحة لحل مشكلات الضرب باعتباره طريقة سريعة للضرب باستخدام القيمة المكانية. ويستخدم النموذج تصميم الصندوق حيث تجزأ الأعداد المضروبة حسب قيمتها المكانية وتكتب خارج الصندوق. ويوضع الناتج داخل مربعات الصندوق ويكون بجموع هذه الأعداد

$$
\text { هو الإجابة لسؤال الضرب. فمثلاً: (3 × } 14 \text { = 42) }
$$

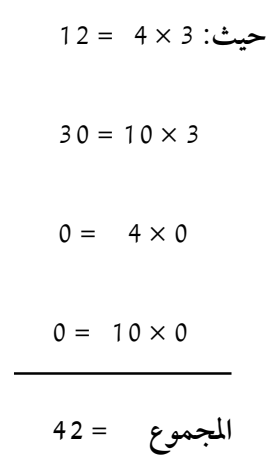

حيث: $35=7 \times$

$100=20 \times 5$

$210=7 \times 30$

$600=20 \times 30$

$645=$
100

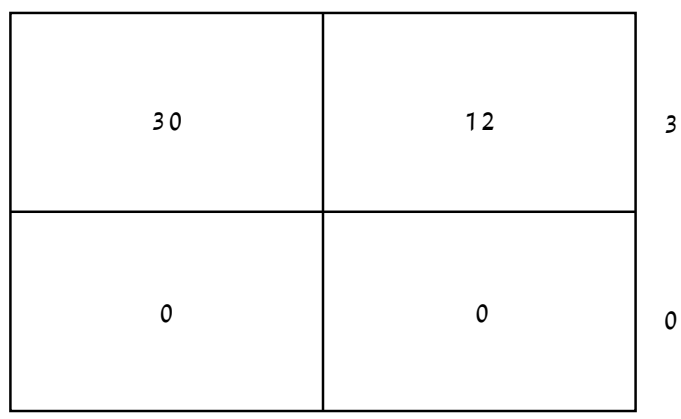

مثال آخر : (35 × 27 =

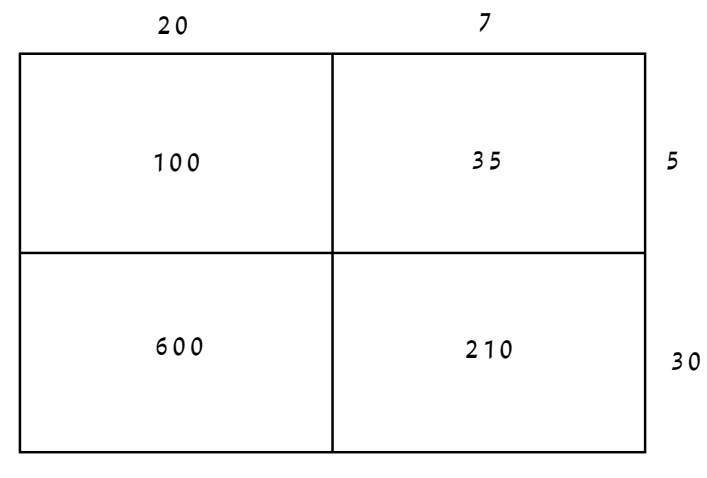


المودل التصويري السنغافوري في مقابل الطريقة الجبرية الرمزية: يدرس التلاميذ في منهج الرياضيات بالمدارس الابتدائية السنغافورية طريقة النموذج حيث تستخدم الرسوم التوضيحية المستطيلة للتصور البصري لبنية وتركيب المشكلة في المشكلة اللفظية المعطاة. وعندما يصل التلاميذ إلى المرحلة الثانوية يتعلموا الطريقة الجبرية لحل المشكلات اللفظية. فالتلاميذ السنغافوريين بالمدارس الابتدائية في أعمار (9-12) سنة يدرسون حل المشكلات اللفظية الجبرية الرمزية باستخدام الرسوم التخطيطية المستطيلة. وفي سنغافورة تعتبر ممارسة استخدام هذه الأنواع من الرسوم التخطيطية معروفة فيما بين المعلمين والتلاميذ ومنها طريقة النموذج المستطيلي أو ما يطلق عليه طريقة النموذج والتي تهدف إلى عرض وبيان الموقف المقدم بالمشكلة اللفظية المعطاة، حيث تمثل المستطيلات bars الكميات المعلومة والمجهولة في المعلومات المعطاة بالمشكلة اللفظية. ومن المتوقع أن يتوصل التلاميذ الي المجهول بتحليل العلاقات بين الوحدات المستطيلة في النموذج بلمهيل إن فاعلية طريقة النموذج السنغافوري ربها تكون نتيجة لاعتمادها علن التمثيل البصري كوسيط لسلسلة التعلم القائمة على تحركات برونر للتعلم من (المحسوس - التصويري- المجرد) و الذي يتبناها منهج رياضيات سنغافورة. فالتلاميذ يمكنهم استخدام الرسوم التخطيطية المستطيلة لحل المشكلة اللفظية التالية بدون معرفتهم للجبر الرمزي: مثال: بقرة وزنها يزيد عن وزن كلب بمقدار 150 كجم. وعنزة وزنها يقل عن وزن البقرة بمقدار 130 كجم، ووزن الحيوانات الثلاث معًا (410) كجم. أوجد وزن البقرة. الحل:

يستخدم التلاميذ في سنغافورة الوحدات المستطيلة للمودل السنغافوري لتمثيل القيم المجهولة و أيضًا العلاقات الكمية الواردة في المشكلة اللفظية. ولا ينتظر التلميذ الوصول الي المدرسة الإعدادية حتى يدرس حل مثل هذه المشكلات عن طريق بناء نظام من المعادلات الجبرية الخطية المتكافئة، 
فالموديل السنغافوري يعطي التلاميذ القدرة على حل المشكلات اللفظية المعقدة مبكرًا، وكذلك المك الاستدلال غير الجبري (Lee \& g,2011, 83)

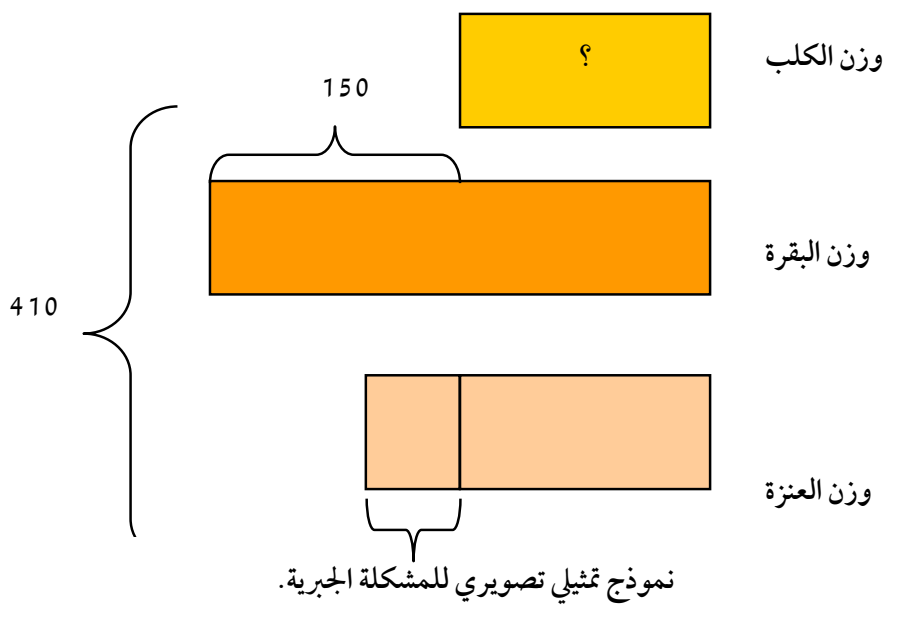

المستطيل الذي يمثل وزن الكلب هنا يعتبر وحدة بجهولة. والمستطيلات التي تمثل البقرة والعنزة تقوم علن المستطيل الذي يميل الكلب. والفرق في الوزن بين الحيوانات والوزن الكلن للحيوانات الثلاثة معلوم؟ والمودل السنغافوري يصبح معادلة تصويرية تمثل 3 وحدات + 170 تساوي 410 $240=170-410$ 3 وحدات مستطيلة = 240 1 وحدة مستطيلة = 240 \% 30 = 80 كجم. وزن البقرة = 80 + $150=0$ ويكون تمثيل المعادلة البصرية يساوئ المعادلة الجبرية: (Looi \& Lim, 2009, 359) س + (س + 150) + (س + 20) = 410، حيث س: تمثل وزن الكلب. إن ضعف تحول التلاميذ من استخدام الرسوم التخطيطية المستطيلة إلى الطريقة الجبرية الرمزية يمكن أن يعوق تعلمهم للجبر (Looi \& Lim, 2009, 359). وفيما يلي حلين لتلاميذ المرحلة الثانوية http://dx.doi.org/10.29009/ijres.4.3.1 
للمشكلات اللفظية. ففي الحل الأول: التلميذ بدأ في تعلم الجبر الرمزي وبالتالي استخدم س لتعبر عن المجهول لكن عملية حلهم للمشكلة لم يؤهلهم للطريقة الجبرية حيث كانت تستلزم: 1- - صياغة أو تكوين معادلة ملائمة.

2- 2 - المعالجة الجبرية للمعادلة.

$$
\text { 3- الحل الجبري للمعادلة. }
$$

4- الترجمة من الحل الجبري إلى الإجابة على السؤال بالمشكلة.

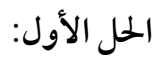

زار (50) طفل المتحف المصري، وكان عدد الأولاد يزيد عن عدد البنات بمقدار (10). فكم عدد

البنات:

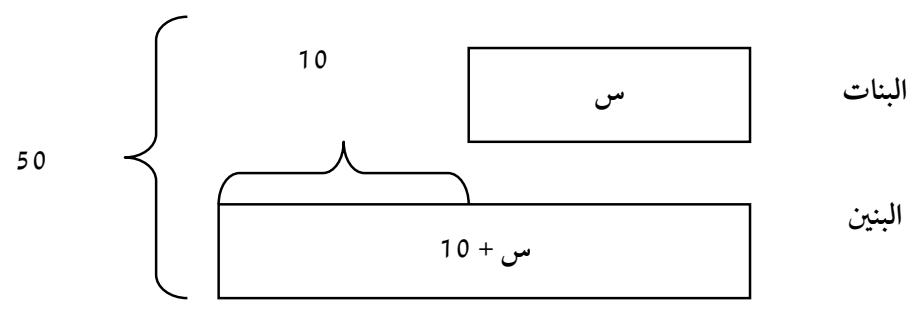

$$
\begin{aligned}
& \text { البنات -س } \\
& \text { البنين - مس + } 10 \\
& 40=10-50 \\
& 20=2 \div 40
\end{aligned}
$$

فالشكل السابق يمثل خليطًا من الرسوم التخطيطية المستطيلة والجبر الرمزي. 
يتشارك فيه ثلاثة أشخاص أ، ب، ج في مبلغ من المال مقداره 210 جنيه. لو أن الشخص (أ) تسلم مبلغًا أقل من الشخص (ب) بمقدار (20) جنيهًا، والشخص (ب) تسلم 3 أمثال الشخص (ج). فكم المبلغ الذي تسلمه الشخص(ج).

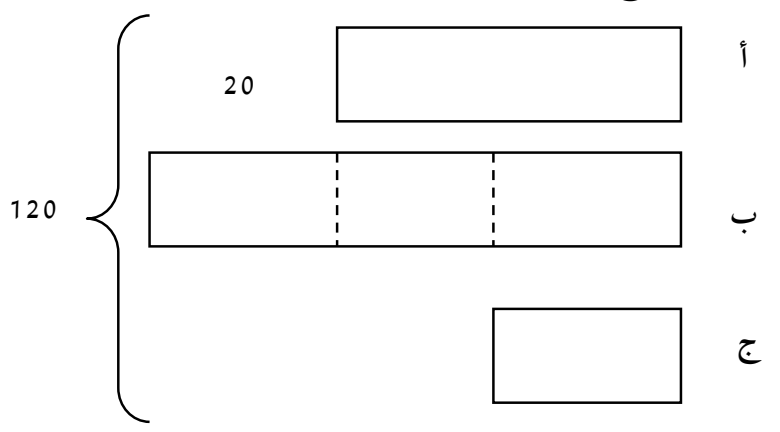

$$
\begin{aligned}
& \text { نفرض أن الشخص ج تسلم س جنيهًا } \\
& \text { بـــــــــ } \\
& \text { أ أبــــ } 3 \text { س - } 20 \\
& 740=20+120 ـ ـ
\end{aligned}
$$$$
\text { س= } 140 \text { × } 7 \text { = } 20 \text { جنيهًا. وبالتالي تسلم الشخص ج (20) جنيهًا. }
$$

وقد يعقد الوصول إلى الاستدلال غير الجبري اكتساب الجبر الرمزي، وبالنسبة لبعض المشكلات اللفظية الجبرية المعروفة مثل هذا الاستدلال يسمح للتلاميذ بالوصول إلى الحل الصحيح بدون الحاجة إلى التعامل مع الأنشطة التمثيلية والتحويلية المرتبطة بالجبر الرمزي. ويستخدم بعض التلاميذ استراتيجية الطريقة المختلطة والتي تجمع بين الطريقة الاستدلالية وسمات الرمز الجبري. والتلاميذ الآخرون ينشئون المودل السنغافوري وبعد ذلك يكتبون معادلته الجبرية المتكافئة قبل الرجوع إلى الطرق الحسابية لحل العمليات. 
ومن المعروف أن التلاميذ ذوي القدرات المنخفضة لديهم صعوبات في استخدام الرمز الجبري

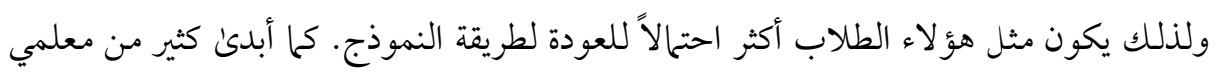

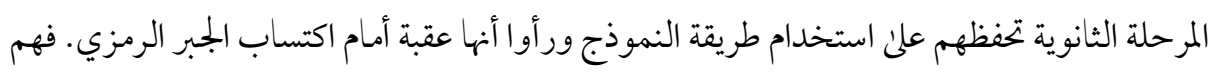
يرون أنها طفولية وغير جبرية (Lee \& Ng,2011, 83). ويشير (Lee \& Ng,2011, 84) إلى تصورات المعلمين بخصوص الفرق بين الطريقتين (الطريقة

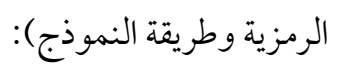
- - لو أن طريقة النموذج حقًا غير جبرية وتقف عقبة أمام تعلم الجبر الرمزي فربما يكون من المستحسن التخلي عن تدريس طريقة النموذج.

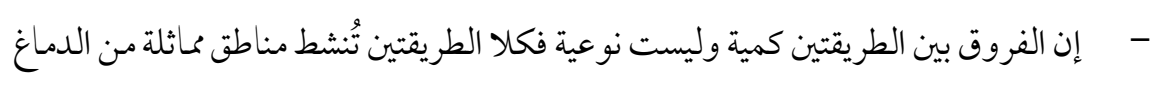
لكن الطريقة الجبرية الرمزية تتطلب مصادر انتباه أكثر.

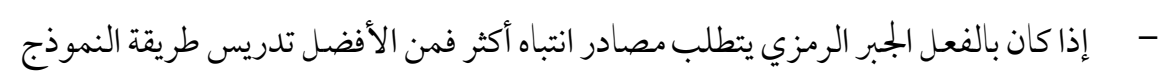

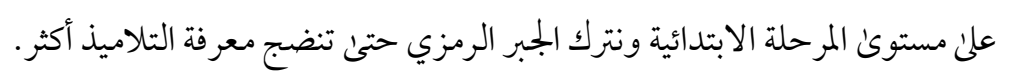

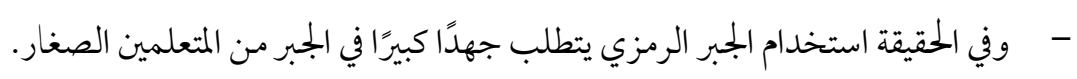

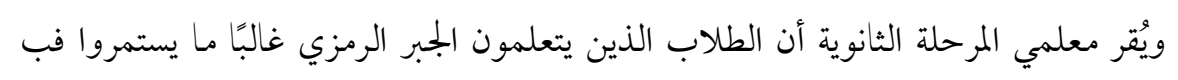

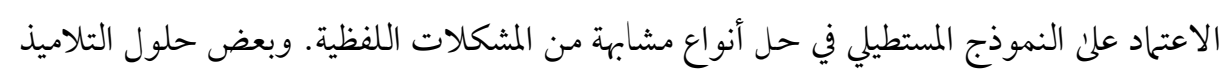

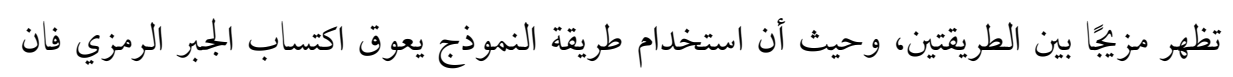

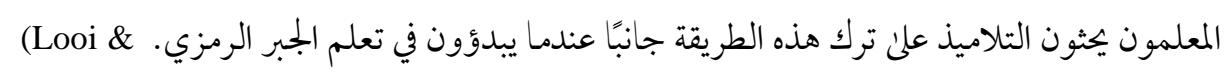

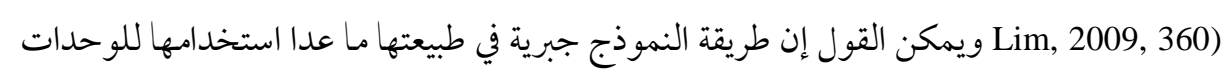

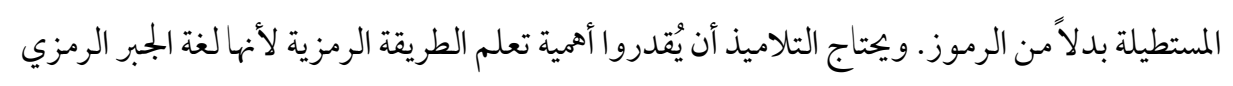
والتي تسود فب الرياضيات العليا. (Looi \& Lim, 2009, 361) 


\section{المثكلات اللفظية التي يمكن حلها باستخدام النموذج السنغافوري مشكلات علاقة الجزء- الكل} في مشكلات علاقة الجزء - الكل يتمم الجزئين الكل، ويوجد نوعين فقط من أسئلة الجزء - الكل (الكل بجهول - الجزء بجهول) مثال: الكل مجهول: أولاد

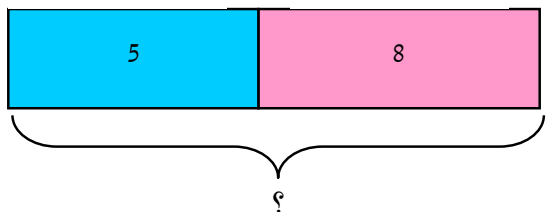

زار عدد من الأطفال ملجأ للأيتام فكان عدد الأولاد (8)، و عدد البنات (5 ). فكم عدد الأطفال الذين زاروا الملججأ؟

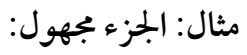
- زار (13) طفلاً دارًا للمسنين، فكان عدد الأو لاد (6) أو لاد. فكم عدد البنات الذين زاروا الدار؟ أولاد

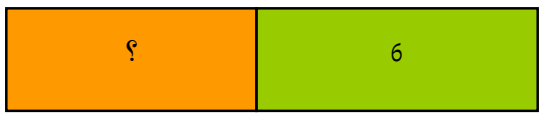


في مشكلات الطرح، يوجد ثلاثة أنواع:

1- الأخذ من taken away: مع سهئ 4 كتب، أعطت لأختها ليلن كتابان. فكم عدد الكتب التي

تبقت معها؟

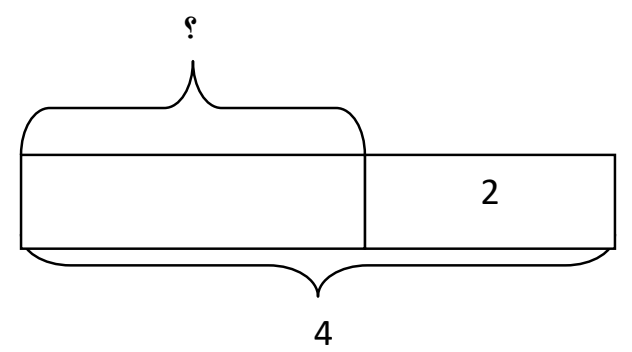

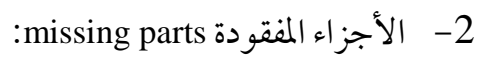

- ياسر معه 6 أقلام. أعطاه محمد أقلام أخرىن. فأصبح مع ياسر 9. فكم عدد الأقلام التي أعطاها محمد لياسر؟

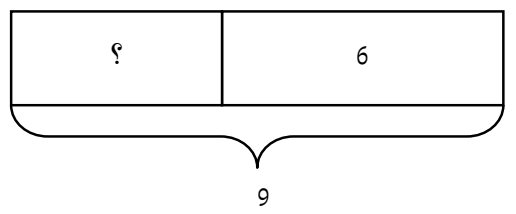

3- - - - ملاقة المقارنة:

- مع حنان خمس قصص، ومع سارة ثلاث قصص. فكم عدد القصص التي تقلها سارة عن حنان؟

5
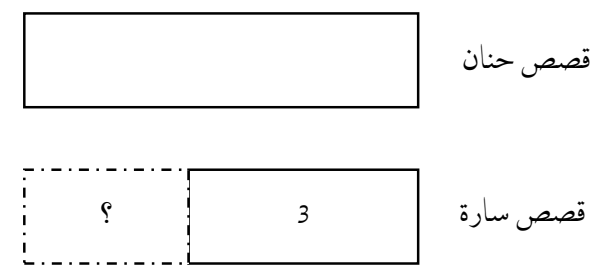

http://dx.doi.org/10.29009/ijres.4.3.1 
مشكلات التغير والمقارنة

مشكلات التغير

توجد مشكلات تبدأ بعلاقة واحدة ثم تتغير:

- - موجد في حوض سمك المدرسة (21) سمكة، منها (15) سمكة قدمها أولياء الأمور و الباقي

اشترته المدرسة. فكم عدد السمك الذي اشترته المدرسة؟

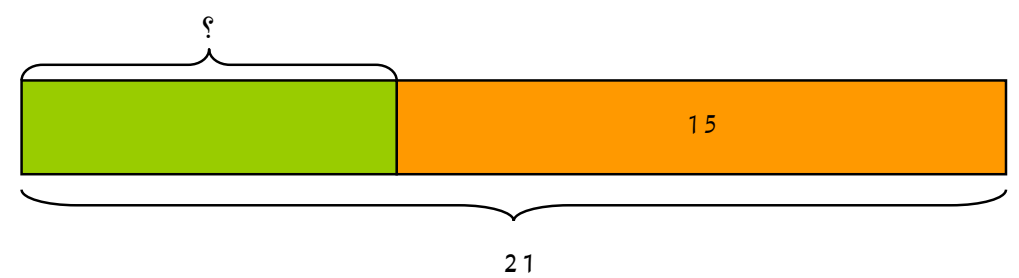

عدد السمك الذي اشترته المدرسة = 21 - 15 = 6 سمكات.

- - لدئ سيف كتب ضعف كتب أدهم. أوجد ما يعطيه سيف لأدهم ليكون مع كلاً منهه| كتاب.
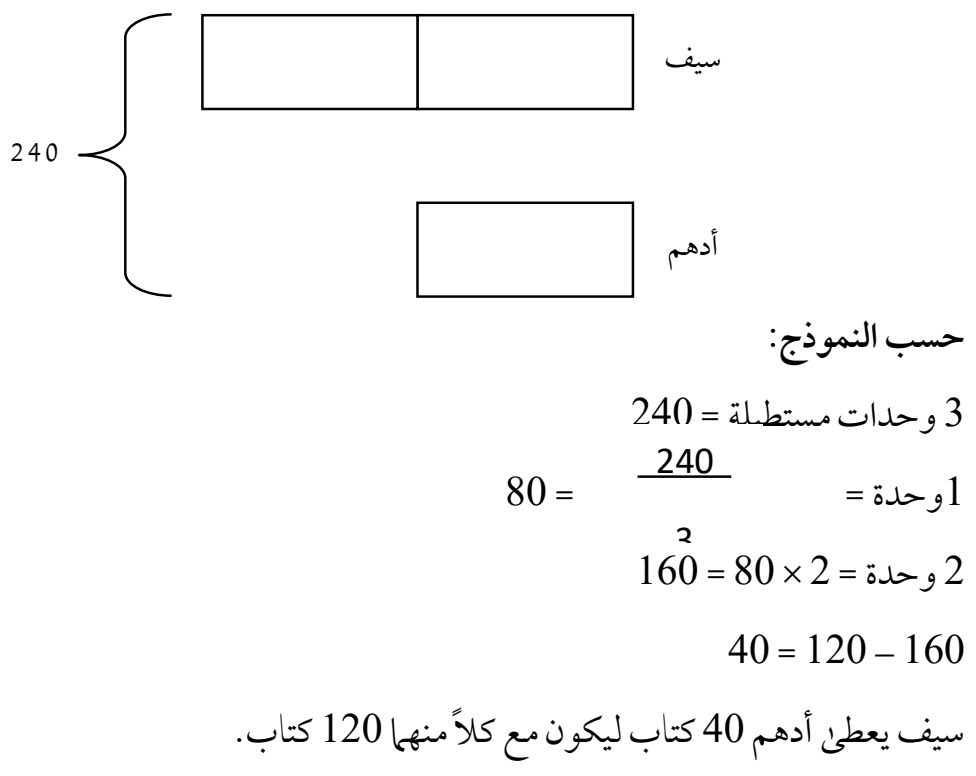

http://dx.doi.org/10.29009/ijres.4.3.1 
- - كسبت نور مبلغًا من المال 3 أمثال ما حصلت عليه في الأسبوع الماضي، وقد كسبت 150

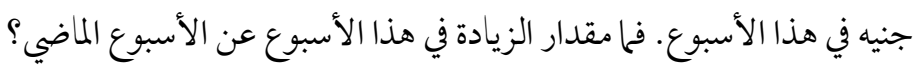

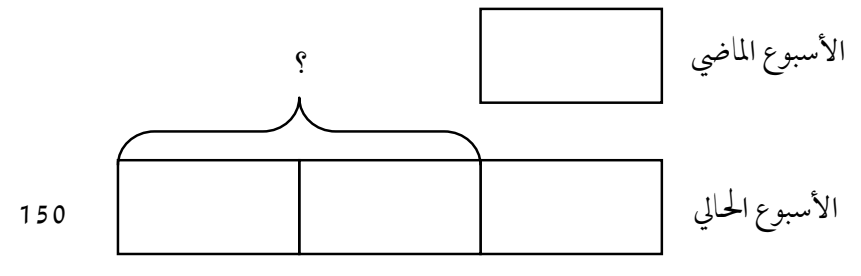

$$
\begin{aligned}
& \text { حسب النموذج: } \\
& 3 \text { وحدات مستطيلة = } 150 \\
& 1 \\
& \text { مقدار الزيادة = } 150 \text { - } 50=00 \\
& \text { مقدار الزيادة هذا الأسبوع } 100 \text { جنيه. } \\
& 1210=1140+70
\end{aligned}
$$

- - سوزان عمرها 3 أمثال عمر ابنة أختها سلمئ الآن. خلال 10 سنوات عمرهما معًا سيكون

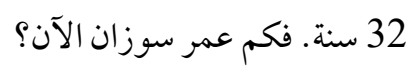

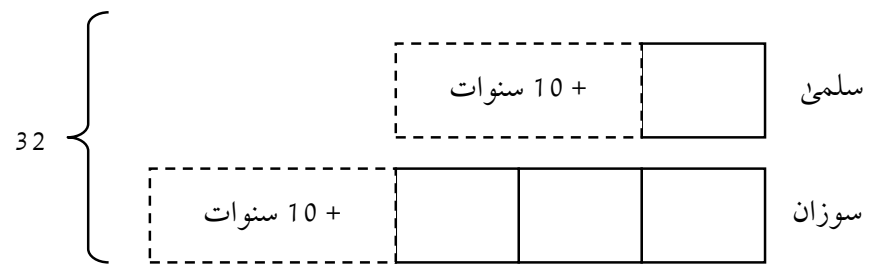

$$
\begin{aligned}
& 12=20-32 \\
& 4 \text { وحدات مستطيلة = } 12 \\
& \text { عمر سلمئ = } 3 \text { سنوات } \\
& 1 \\
& \text { عمر سوزان = } 9 \text { سنوات } \\
& 3 \text { و وحدات =3×3 } \\
& \text { الفحص = } 32=20+3
\end{aligned}
$$




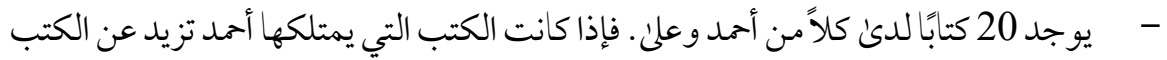

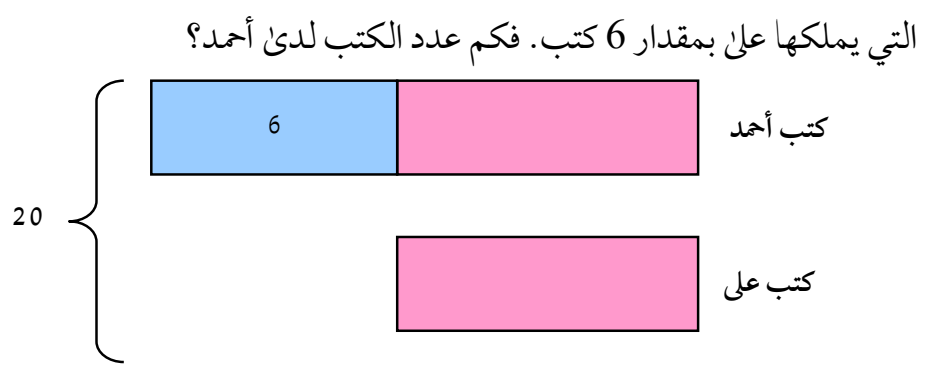

$$
\begin{aligned}
& \text { الحل: } \\
& \text { حسب النموذج: } \\
& 14=6-20 \\
& 2 \text { وحدة مستطيلة = } 14 \\
& 1 \\
& \text { كتب أحمد = } 7 \text { + } 6 \text { = } \\
& \text { الفحص: } 13 \text { + } 70 \text { = }
\end{aligned}
$$

- اشترئ مجموعة أفراد تذاكر لحديقة متحف بمبلغ 720 جنيهًا. سعر تذكرة الكبار (15) جنيهًا، وسعر تذكرة الطفل (8) جنيهات. فإذا كان عدد الكبار يزيد عن عدد الأطفال بمقدار

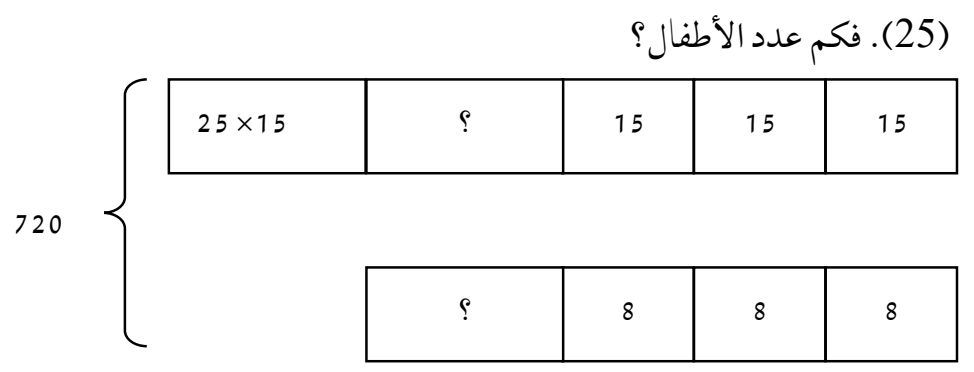

http://dx.doi.org/10.29009/ijres.4.3.1 


$$
\begin{aligned}
& \text { الحلى: } \\
& 375=25 \times 15 \\
& \text { حسب النموذج: } \\
& 345=375-720 \\
& 15 \\
& 345 \text { وحدة } \\
& 23=15 \div 345=? \\
& 15=23 \div 345 \\
& \text { الفحص: } \\
& (8 \times 15)+(15 \times 25)+(15 \times 15)
\end{aligned}
$$

- - مع نهى قواقع بحرية تزيد عن هبة بمقدار (50). وقواقع منى أقل من قواقع نهل بمقدار

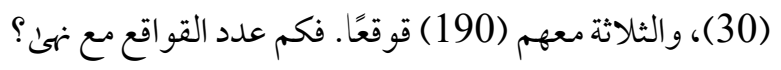

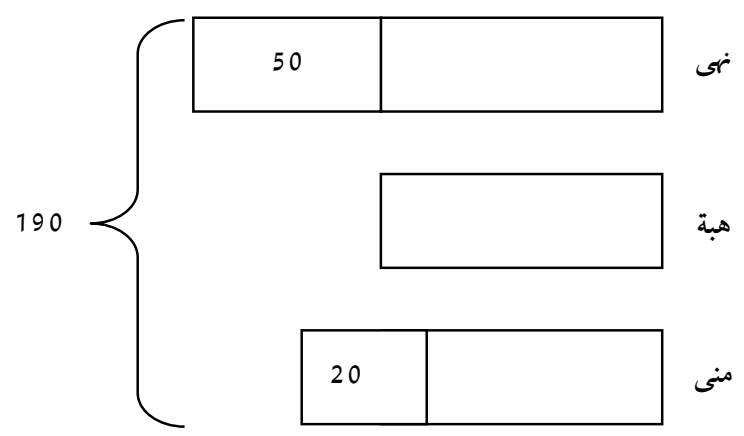




$$
\begin{aligned}
& \text { الحل: } \\
& \text { حسب النموذج: } \\
& 120=70-190 \\
& 3 \text { وحدات مستطيلة = } 120 \\
& 10 \text { وحدة = } 120 \\
& \text { قو اقع نهى = } 40 \text { + } 50 \text { = } 90 \text { بحريًا } \\
& \text { مع نهى } 90 \text { قوقعًا بحريًا. }
\end{aligned}
$$

- - في مزرعة العم فرغلي يوجد 19 أوزه ودجاجة وبطة، عدد الدجاج يزيد عن عدد الأوز بمقدار 3، أما البط فيقل عن الأوز بمقدار 2. فكم عدد البط؟

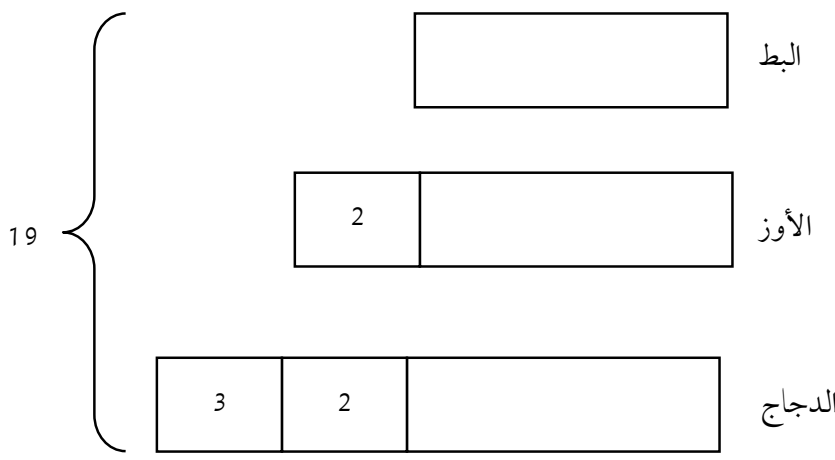

$$
\begin{aligned}
& \text { الحل: } \\
& \text { حسب النموذج: } \\
& 12=7-19 \\
& 3 \text { وحدات مستطيلة= } 12 \\
& 1 \text { و وحدة = } 4 \text { = } 4 \text { = } \\
& \text { عدد البط = } 4 \text { بطة }
\end{aligned}
$$




$$
\begin{aligned}
& \text { عدد الأوز = } 4=2 \text { = } \\
& \text { عدد الدجاج= } 4 \text { + } 2 \text { + } 3 \text { = } 9 \text { دجاجة } \\
& \text { الفحص= } 19=9+6 \text { + }
\end{aligned}
$$

- وفر ثلاثة أصدقاء مروة وياسمين ونورا مبلغًا من المال في الصيف. مروة وفرت 545 جنيه، ووفرت ياسمين 630 جنيه، ووفرت نورا مبلغًا يزيد عها وفرته ياسمين بمقدار 35 جنيه. فما

المبلغ الذي وفره الثلاثة أصدقاء؟

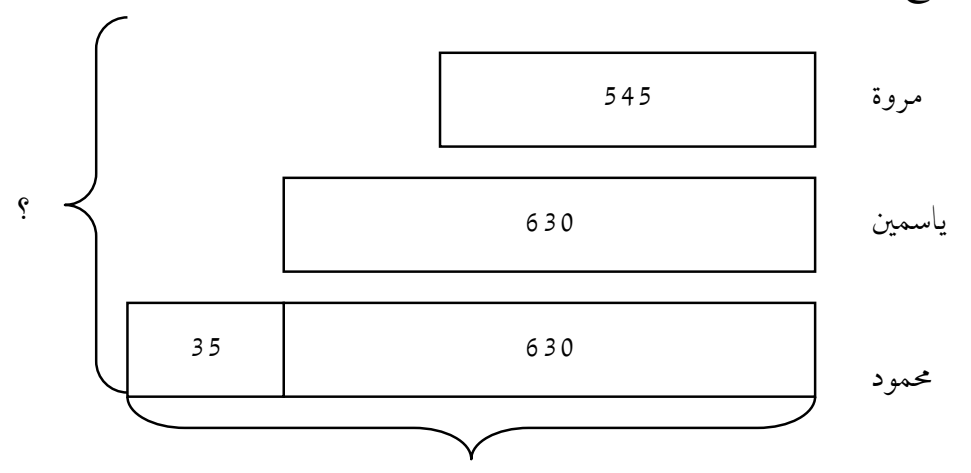

665

المبلغ الذي وفره الأصدقاء الثلاثة = 545 + 630 + 665 = 1840 جنيه. 


\section{مشكلات الكسور والنسب}

يمكن استخدام المودل السنغافوري في حل المشكلات التي تتضمن الكسور والنسب المئوية: - صرف أحمد 2/ 5 من نقوده عند شرائه قصة. وكانت ثمن القصة 12 جنيه. فكم المبلغ الذي

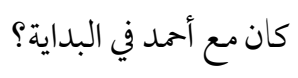

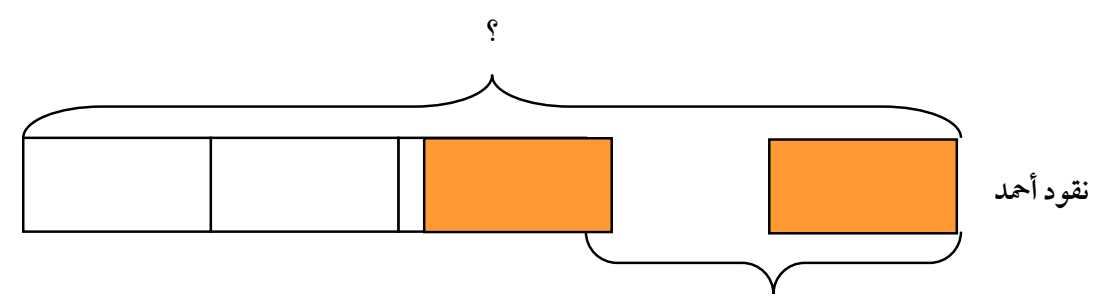

$$
6=2 \div 12=1
$$$$
\text { 5 وحدات = } 30=6 \text { × }
$$

أحمد كان معهد في البداية 30 جنيًا.

Fraction model نموذج الكسور

- - إذا كان عدد الأو لاد 3/ 5 من البنات، فلو كان عدد البنات 75 بنتًا. فكم عدد الأولاد؟

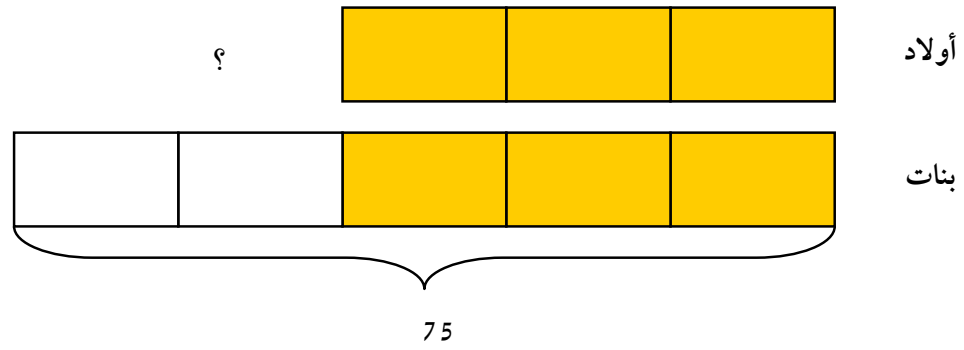

http://dx.doi.org/10.29009/ijres.4.3.1 


$$
\begin{aligned}
& \text { الحلى: } \\
& \text { حسب النموذج: } \\
& 5 \text { و حدات مستطيلة = } 75 \\
& 15=5 \div 75=5 \text { و } 15 \\
& \text { 3 وحدات = } 35 \text { = } 35 \\
& \text { عدد الأو لاد = } 45 \text { ولد. }
\end{aligned}
$$

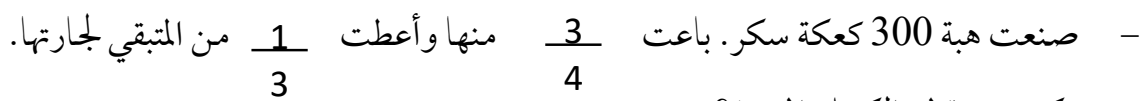

فكم عدد قطع الكعك المتبقية؟
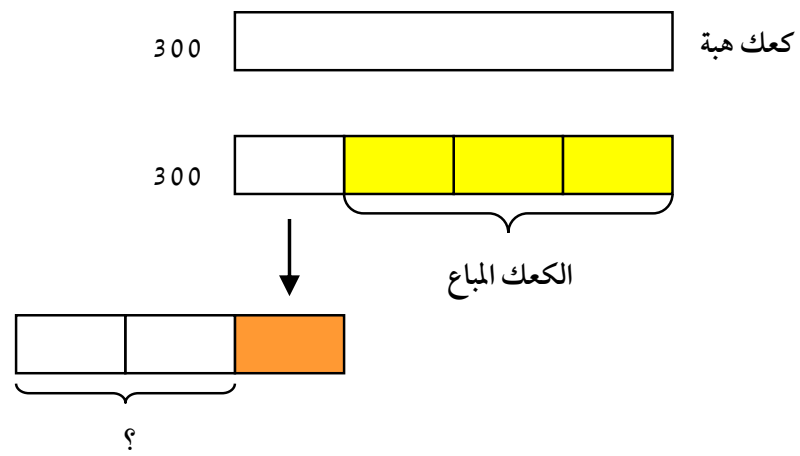

$$
\begin{aligned}
& \text { باعت منها }
\end{aligned}
$$

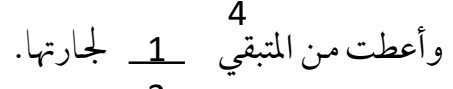

$$
\begin{aligned}
& \text { فكم عدد قطع الكعك المتبقية؟ } \\
& 4 \text { و حدات - مستطيلة = } 300 \\
& 15 \text { و حدة = } 75 \\
& 3 \text { و حدات = } 75 \text { (المتبقي من الكعك) } \\
& 1 \\
& \text { 2 و حدة = } 50 \text { = } 25 \\
& \text { تبقى مع هبة } 50 \text { كعكة سكر. }
\end{aligned}
$$



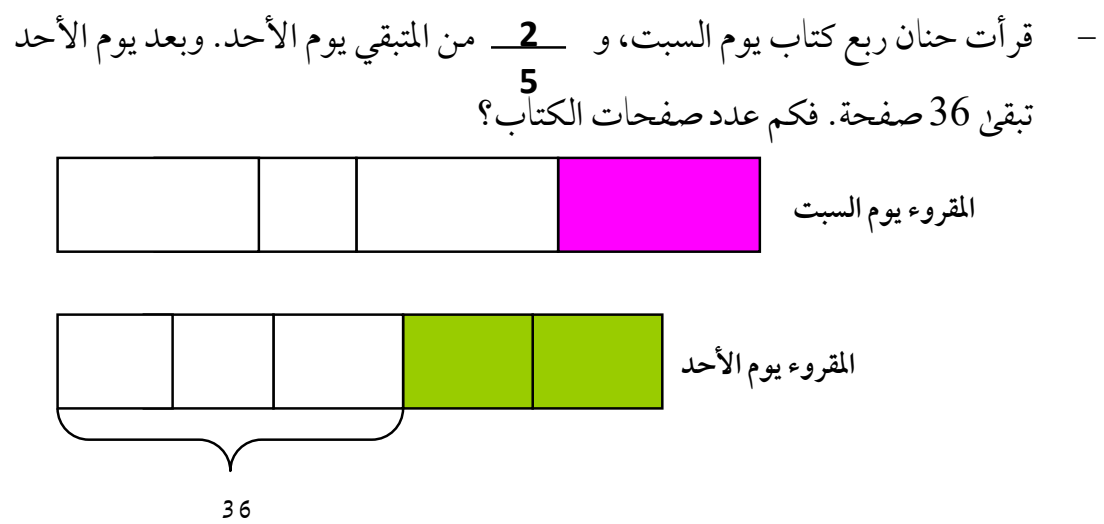

$$
\begin{aligned}
& \text { حسب المستطيل الاسفل: } \\
& 36 \text { و وحدات } \\
& 12 \text { و وحدة } 12 \\
& \text { 5 وحدات = } 60 \text { = } 50 \\
& \text { حسب المستطيل الأعلى: } \\
& \text { 3 وحدات = } 60 \\
& 10 \\
& 40 \text { و وحدات } \\
& \text { عدد صفحات الكتاب = } 80 \text { صفحة. }
\end{aligned}
$$


- دفعت منى 36 جنيه عند شر ائها وجبة عشاء، وهذا المبلغ يمثل 15 ٪ من راتبها. فكم يكون راتبها.
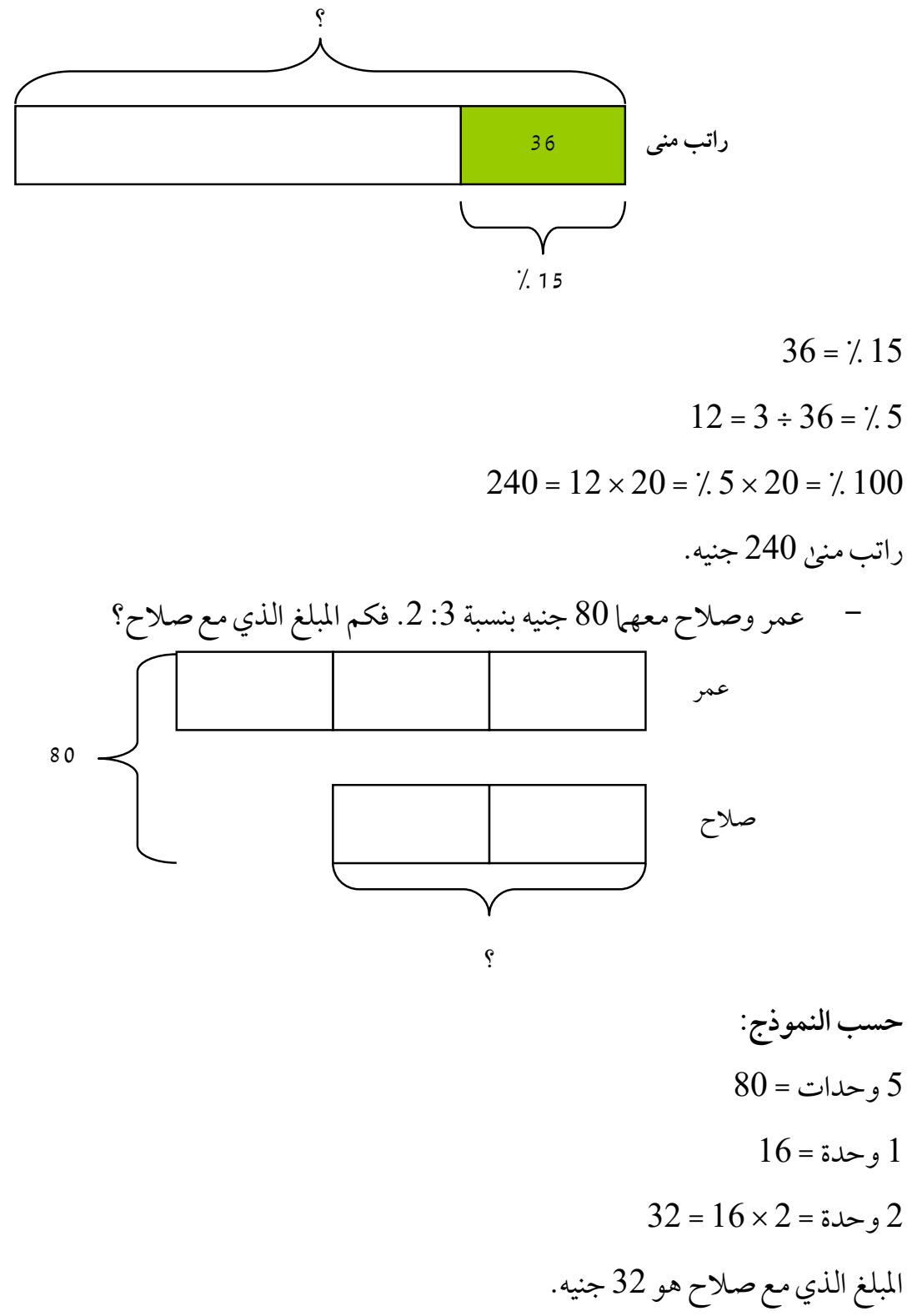

http://dx.doi.org/10.29009/ijres.4.3.1 
- اشترئ ثلاثة أصدقاء أحمد ومحمد ومحمو دعدد من الطو ابع بنسبة 3: 5: 7 ـ فلو أن محمد تسلم 45 طابع. فكم عدد الطو ابع التي تسلمها محمود وتزيد عن عدد طو ابع أحد؟

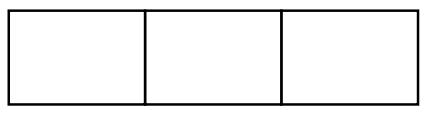
طوابع أحمد
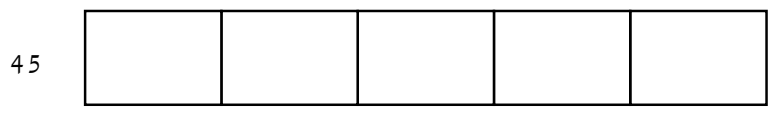
طو ابع محمد

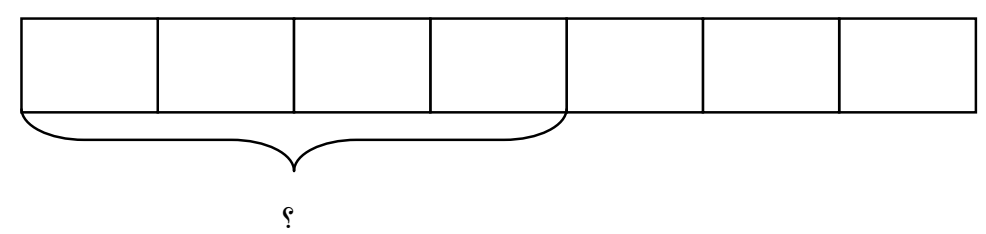
طوابع محمود حسب النموذج: 5 وحدات مستطيلة = 45

$$
9=1
$$

$$
\text { 3وحدات = } 3 \text { × } 3 \text { × } 27 \text { (طوابع أحمد) }
$$$$
7 \text { وحدات =7 × } 73 \text { × } 63 \text { (طوابع محمود) }
$$
عدد الطوابع التي يزيدها محمود عن أحمد = 63 - 27 = 36 طابع 


\section{References:}

- $\quad$ Bisk, R. \& Hogan, R. (2007). The Singapore Math Model Workshop: Teaching for Mastery and Understanding. Grades K-5, Sofitel Hotel, November 2. available at: http://www.greatsource.com/GreatSource/pdf/SingaporeFlier0907.pdf

- $\quad$ Bisk, R. (2010). Problem Solving with Model Drawing. From:

- $\quad$ Cai, J. \& Moyer, J. (2007). Developing Algebraic Thinking in Earlier Grades: Some Insights from International Comparative Studies. available at: http://www.math.udel.edu/LIECAL/papers/YearbookCaiMoyer29_final_.p df

- Chen, S., Logan, N., Pfister, M. \& Nowicki, J. (2010). Primary Singapore Mathematics: A Revolutionary Program Designed to Improve Student Mathematics Achievement. From:

- $\quad$ Cheong, Y. K., \& Consultancy, M. (2002). The model method in Singapore. The Mathematics Educator, 6(2), 47-64.

- $\quad$ Clark, A. (2009). Problem solving in singapore math. Diambil pada tanggal, 29.

- $\quad$ Clark, A. (2013). Singapore math: A visual approach to word problems. Math in Focus.

- $\quad$ Clark, S. (2008). Singapore Math Strategies. available at: http://institute2008.wikispaces.com/file/view/Snapshot+of+Singapore+Mat h.pdf

- $\quad$ Forsten, Ch. \& Stipek, A. (2010). Model Drawing On-Site Training for 1-6 Educators.From:http://www.sde.com/downloads/collateral/SS_MWM_Mo delDrawing.pdf.

- Hoven, J. \& Garelick, B. (2007). Singapore Math: Simple or Complex?

Educational leadership Making Math Count, 65(3),28-31. available at: http://www.nychold.com/art-hoven-el-0711.pdf.

- $\quad$ Kam, H. \& Gopinathan, S. (1999). Recent Developments in Education in Singapore. National Institute of Education, Singapore, 10(1), 99-117. 
- $\quad$ Kheong, F. (2009). Math in Focus: The Singapore Approach the Underpinning Concept. available at: http://ar.scribd.com/doc/37660379/Math-in-FocusThe-Singapore-Approach-The-Underpinning-Concept

- $\quad$ Kron, J. (2009). Problem Solving with Model Drawing. NCCTM's 39th Annual State Conference, North Carolina Teacher Academy, October 30. available at: http://teacheracademy.org/docs/Math_model_drawing_09.ppt

- $\quad$ Lee, K. \& Ng, S. (2011). Neuroscience and the Teaching of Mathematics. National Institute of Education. Singapore Educational Philosophy and Theory, 43(1), 81-86.

- $\quad$ Looi, C. \& Lim, K. (2009). From bar diagrams to letter-symbolic algebra: a technology-enabled bridging. Journal of Computer Assisted Learning, 25, 358-374.

- $\quad$ Stipek, A. (2011). Singapore Math Strategies: Model Drawing for Grades 1-6. available at: https://www.ed2go.com 
$\bar{x}$ 